\title{
Could aerosol emissions be used for regional heat wave mitigation?
}

\author{
D. N. Bernstein ${ }^{1,2}$, J. D. Neelin ${ }^{2}$, Q. B. $\mathbf{L i}^{2}$, and D. Chen ${ }^{2}$ \\ ${ }^{1}$ Department of Soil and Water Sciences, Robert H. Smith Faculty of Agriculture, Food and Environment, The Hebrew \\ University of Jerusalem, POB 12, Rehovot 76100, Israel \\ ${ }^{2}$ Department of Atmospheric and Oceanic Sciences, University of California, Los Angeles, 405 Hilgard Ave., Los Angeles, \\ CA 90095, USA
}

Correspondence to: J. D. Neelin (neelin@atmos.ucla.edu)

Received: 3 July 2012 - Published in Atmos. Chem. Phys. Discuss.: 12 September 2012

Revised: 8 May 2013 - Accepted: 8 May 2013 - Published: 5 July 2013

\begin{abstract}
Geoengineering applications by injection of sulfate aerosols into the stratosphere are under consideration as a measure of last resort to counter global warming. Here a potential regional-scale application to offset the impacts of heat waves is critically examined. Using the Weather Research and Forecasting model with fully coupled chemistry (WRFChem), the effect of regional-scale sulfate aerosol emission over California in each of two days of the July 2006 heat wave is used to quantify potential reductions in surface temperature as a function of emission rates in a layer at $12 \mathrm{~km}$ altitude. Local meteorological factors yield geographical differences in surface air temperature sensitivity. For emission rates of approximately $30 \mu \mathrm{g} \mathrm{m}^{-2} \mathrm{~s}^{-1}$ of sulfate aerosols (with standard WRF-Chem size distribution) over the region, temperature decreases of around $7{ }^{\circ} \mathrm{C}$ result during the middle part of the day over the Central Valley, one of the areas hardest hit by the heat wave. Regions more ventilated with oceanic air such as Los Angeles have slightly smaller reductions. The length of the hottest part of the day is also reduced. Advection effects on the aerosol cloud must be more carefully forecast for smaller injection regions. Verification of the impacts could be done via measurements of differences in reflected and surface downward shortwave. Such regional geoengineering applications with specific near-term target effects but smaller cost and side effects could potentially provide a means of testing larger scale applications. However, design considerations for regional applications, such as a preference for injection at a level of relatively low wind speed, differ from those for global applications. The size of the required injections and the necessity of injection close to the target region raise substantial concerns. The evaluation of this regional-scale application is thus consistent with global
\end{abstract}

model evaluations, emphasizing that mitigation via reduction of fossil fuels remains preferable to considering geoengineering with sulfate aerosols.

\section{Introduction}

Global surface temperatures are expected to rise over the coming century due to the ongoing emission of greenhouse gases, with attendant changes in frequency of extreme events such as heat waves (IPCC, 2007). Geoengineering solutions are under discussion as a potential means of offsetting this rise. A particular solution that has been proposed involves injecting aerosol-forming compounds or aerosols into the stratosphere and cooling the earth's surface by reflecting incoming shortwave flux. Initially proposed by Budyko (1974), this has been controversial for obvious reasons. Because the effort to reduce greenhouse gas emissions is failing, the proposal has come into renewed discussion. Following serious consideration by Keith (2000) and Crutzen (2006), there have been a number of studies quantifying the effects of various strategies for intervention with sulfate aerosols at the global scale (Rasch et al., 2008a; Robock et al., 2008; Brovkin et al., 2009; Jones et al., 2010; Kravitz et al., 2011; Niemeier et al., 2011; Volodin et al., 2011; Ricke et al., 2011), and a number of studies raising substantial concerns regarding side effects (Matthews and Caldeira, 2007; Trenberth and Dai, 2007; Robock, 2008; Tilmes et al., 2008; Heckendorn et al., 2009; Kravitz et al., 2009; Robock et al., 2010). Crutzen (2006) estimated that the insertion of approximately $5 \mathrm{Tg} \mathrm{yr}^{-1}$ of sulfur would be required to balance the impact of greenhouse gas warming in the case of a double- $\mathrm{CO}_{2}$ emission scenario. 
Wigley (2006) suggested that an annual $5 \mathrm{Tg}$ sulfur flux would be sufficient, alongside a reduction in emissions, while Pierce et al. (2010) and English et al. (2012), who found less effectiveness, consider $10 \mathrm{Tg} \mathrm{S} \mathrm{yr}^{-1}$. The geoengineering injection of sulfate aerosols can be compared to those coming from a volcanic eruption. For example, the eruption of Mount Pinatubo in June of 1991 released an estimated $20 \mathrm{Tg}$ of $\mathrm{SO}_{2}$, which caused up to $2{ }^{\circ} \mathrm{C}$ of cooling in surface temperatures with Northern Hemisphere continents in the summer of 1992 (Robock, 2000, 2002; Soden et al., 2002). Rasch et al. (2008a) pointed out that the impact of the aerosol emissions depends on the size of the inserted aerosols, and that smaller-sized aerosols scatter more efficiently provided that these are not too small, and that the total mass is conserved.

We here use a setup of the the Weather Research and Forecasting model with fully coupled chemistry (WRF-Chem) (Grell et al., 2005) that has been used for air quality studies over California (Chen et al., 2010) to provide a modelbased evaluation of one potential application of geoengineering. It is worth underlining that the technology to do such an experiment in the real world does not currently exist, but there is active research on such methods, including patent applications (Chan et al., 2010). Given this, it is important to have model-based studies to help to put into perspective what would be implied if such methods should become available. Here a model developed for other purposes can contribute at low cost to particular aspects of understanding the issues involved.

In particular, this study examines whether aerosol injections, specifically those that are being considered for globalscale geoengineering, could be applied at the regional scale with the timing chosen to mitigate heat waves, or excessively hot weather events. If negative impacts of global warming create pressure for regional planners to enact geoengineering solutions, there are a number of factors that may bring regional-scale interventions to the forefront of the debate. Regional actions might involve less concerted effort and less international cooperation than a global-scale application. Because global warming is tending to affect regions differently, regional geoengineering solutions could prove more feasible than their proposed global counterparts. Finally, smallerscale solutions could potentially provide a means of testing the larger scale applications. However, the design considerations are not exactly the same; here we consider injection of sulfate aerosols to impact shortwave radiation on a time scale less than a day in the regional application. Global applications allow for longer evolution time, which may include gas-phase formation of sulfate aerosols. Several recent studies (Heckendorn et al., 2009; Pierce et al., 2010; English et al., 2012, and references therein) have examined extensively the efficacy of various injection methods, involving $\mathrm{SO}_{2}, \mathrm{H}_{2} \mathrm{SO}_{4}$, or $\mathrm{SO}_{4}^{2-}$, for producing desired sulfate aerosol size distribution in the global application.

English et al. (2012) compared the efficacy of injecting three different sulfur species: $\mathrm{SO}_{2}$ gas, $\mathrm{H}_{2} \mathrm{SO}_{4}$ gas, and $\mathrm{SO}_{4}^{2-}$ particles. They found that injecting $\mathrm{SO}_{4}^{2-}$ particles instead of $\mathrm{SO}_{2}$ gas increases the sulfate burden and that injecting $\mathrm{H}_{2} \mathrm{SO}_{4}$ gas instead of $\mathrm{SO}_{2}$ does not discernibly alter sulfate size or mass. In one simulation, they found that injecting $\mathrm{SO}_{4}^{2-}$ particles with a lognormal distribution of width 1.5 and peak radius of $0.1 \mu \mathrm{m}$ produces $51 \%$ higher mass burdens than $\mathrm{SO}_{2}$ injection in a narrow region. Additionally, a $\mathrm{SO}_{4}^{2-}$ particle injection instead of $\mathrm{SO}_{2}$ gas results in smaller particles. The higher mass burden and smaller effective radius lead to significantly higher aerosol optical depth. The present study focuses instead on the regional aspects, using an assumed direct injection of a certain size distribution of sulfate particles. We note that there is currently no technical means to emit such aerosols as particles. The aspect of the problem considered here emphasizes advection and regionalscale impacts, while using a standard source treatment from WRF-Chem. The aim is to provide a sense of the meteorological factors that would need to be taken into account in evaluating any such potential application. Before any such application could be undertaken, the microphysical aspects of forming such particles in the atmosphere should also be taken into account.

We choose the heat wave of July 2006 in California as a case study. During this abnormal event, extremely hot surface temperatures were observed, resulting in a death toll estimated to exceed 140 (Ostro et al., 2009). The heat wave lasted for 17 days and peaked on 23 July (Gershunov et al., 2009). Figure 1 shows surface air temperatures simulated by the WRF model for 22 and 23 July, as detailed in Sect. 3. The simulated highest temperatures in California were in a narrow region in the Central Valley between the ventilated coastal area and mountain ridge (see the Supplement for surface air temperatures and upper-level flow patterns from the North American Regional Reanalysis (Mesinger et al., 2006)). The upper-level flow field is northerly over much of the domain at 200 mbar with speeds ranging from roughly 4 to $14 \mathrm{~m} \mathrm{~s}^{-1}$ over California. Heat waves may not evolve in exactly the same manner in future climate, and the details of how such an experiment would be conducted would differ depending on the meteorological conditions under consideration. However, the example of the recent heat wave serves to provide an upper-level flow field of reasonable magnitude and pattern, which is important to the advection of emitted aerosols, as well as a temperature simulation that yields high temperatures in a geographic pattern that is meteorologically reasonable.

The first point to address is whether advection rapidly carries the emitted aerosols away from the target region. Subsequent points of examination are quantifying the potential size of the reduction in surface solar radiation and reduction in surface air temperature (relative to the control simulation) for a given size of injection, as well as whether the meteorology of certain regions makes such experiments more or less effective. 


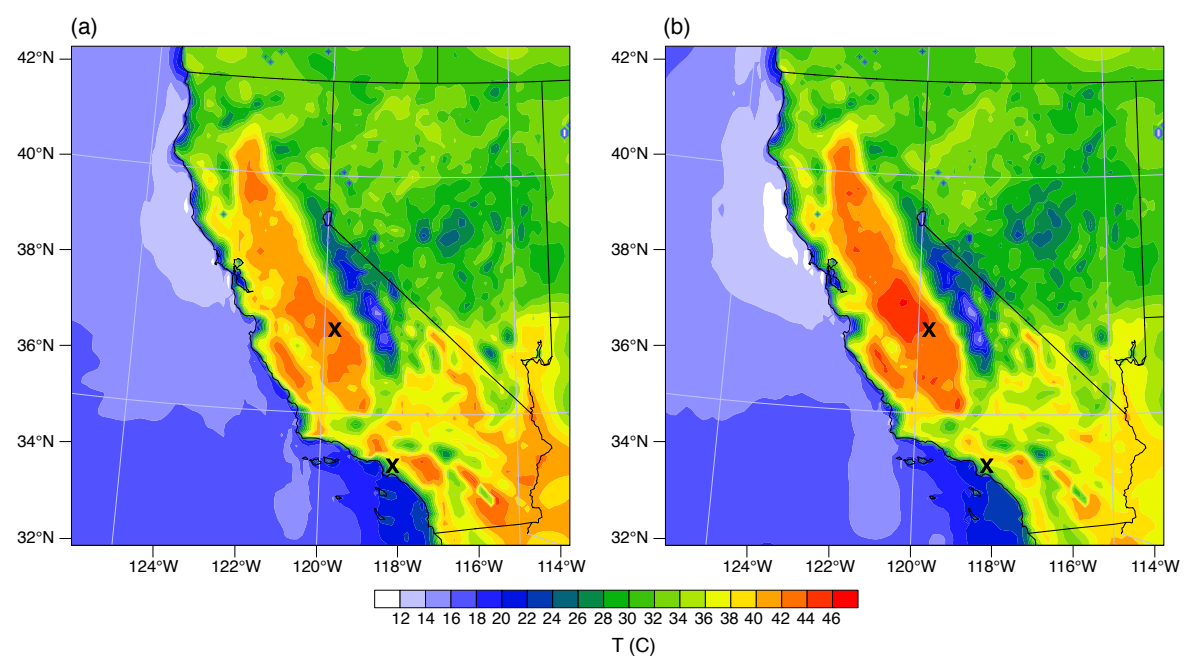

Fig. 1. Surface air temperature $\left({ }^{\circ} \mathrm{C}\right)$ simulated by WRF for (a) 22 July 2006 and (b) 23 July 2006 over California and Nevada at 16:00 LT. Crosses show the sample locations in Los Angeles and the Central Valley used in Fig. 2.
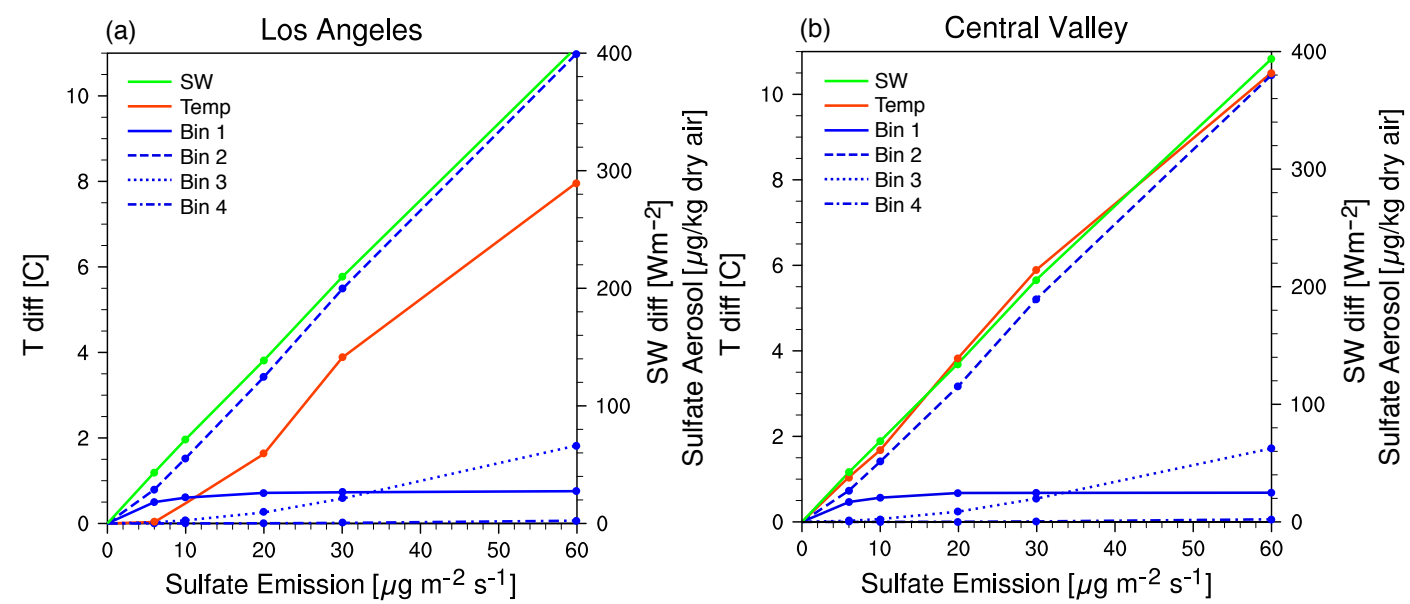

Fig. 2. Sulfate aerosol mixing ratio in each bin $\left(\mu \mathrm{g} \mathrm{kg} \mathrm{g}^{-1}\right.$ of dry air) at the level of the injection with surface temperature $\left({ }^{\circ} \mathrm{C}\right)$ and surface shortwave flux $\left(\mathrm{Wm}^{-2}\right)$ differences as a function of the amplitude of sulfate aerosol emissions $\left(\mu \mathrm{g} \mathrm{m}^{-2} \mathrm{~s}^{-1}\right)$ for the large-scale experiment at 13:00 LT on 22 July for (a) a point in Los Angeles and (b) a point in the Central Valley (Fresno). See Fig. 1 for point locations. See Sect. 2 for bin sizes, defined by dry particle diameter.

\section{Setup and experiments}

The Weather Research and Forecasting model with fully coupled chemistry (WRF-Chem) (Grell et al., 2005; Grell, 2008; Grell et al., 2011) is applied to simulate the impact of low stratospheric sulfate aerosols. The WRF-Chem is a nonhydrostatic mesoscale model that uses a terrainfollowing, hydrostatic-pressure vertical coordinate with the top of the model being a constant pressure surface. The horizontal structure of the model grid is the Arakawa-C grid. Here, the time integration scheme in the model uses a third-order Runge-Kutta scheme. The Yonsei University scheme (YSU, (Hong et al., 2004)) is used to parameterize the planetary boundary layer and Grell 3-D ensemble scheme (Grell and Devenyi, 2002) for convective parameterization. The NOAA land-surface model (Chen and Dudhia, 2001) is used. The chemistry package includes dry deposition, aqueous-phase chemistry coupled to some of the microphysics and aerosol schemes, biogenic emissions, anthropogenic emissions, chemical mechanisms, photolysis schemes, and aerosol schemes (Grell et al., 2005; Fast et al., 2006; Zaveri et al., 2008). The Model for Simulating Aerosol Interactions and Chemistry (MOSAIC) (Fast et al., 2006; Zaveri et al., 2008; Barnard et al., 2010) has been used for aerosol treatment. MOSAIC distributes aerosols according to their dry size into the discrete bins and calculates the mass and number for each bin. The standard option, four bins $(0.039-0.156,0.156-0.625,0.625-2.5,2.5-10.0 \mu \mathrm{m}$ dry 
(a)

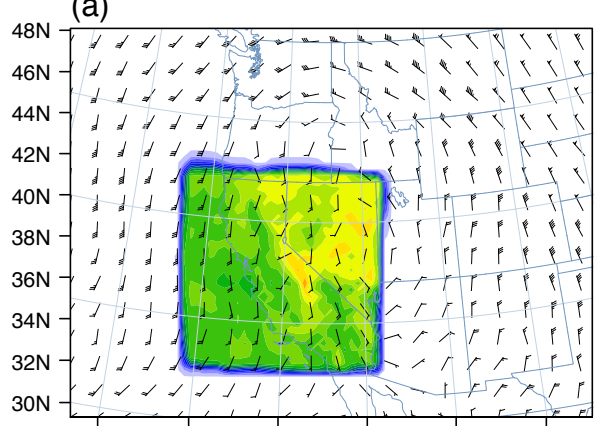

(c)

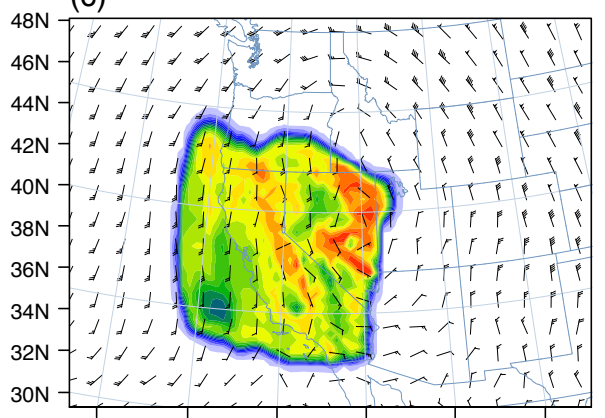

(e)

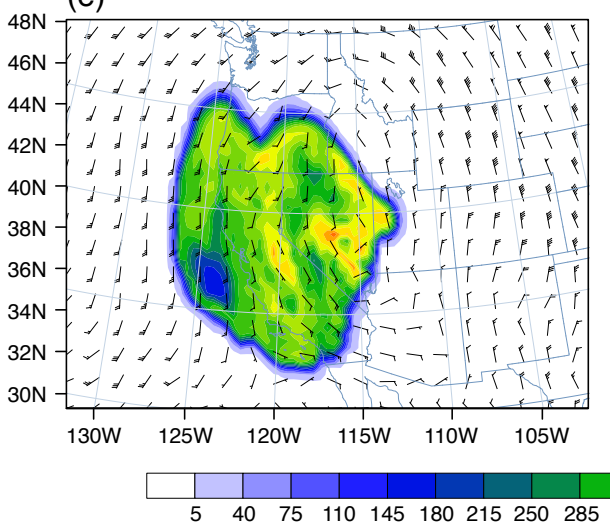

(b)

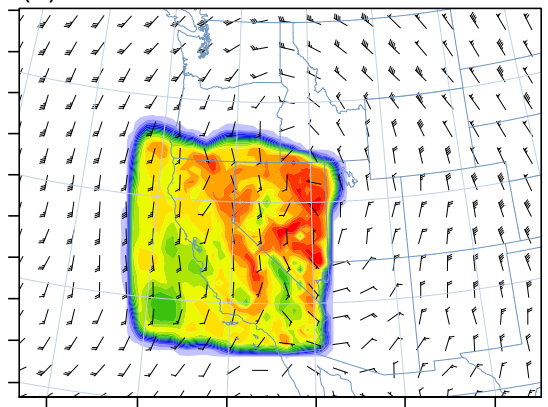

(d)

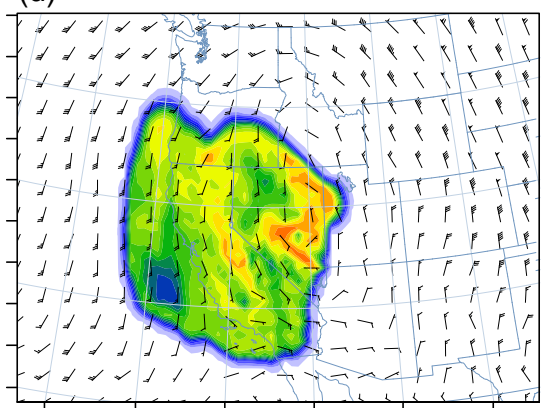

(f)

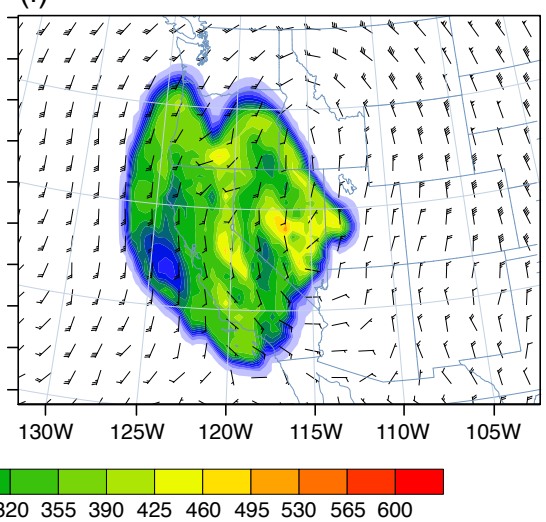

Fig. 3. Bin $2(0.156-0.625 \mu \mathrm{m})$ sulfate aerosol mixing ratios ( $\mu \mathrm{g} \mathrm{kg}^{-1}$ of dry air) and wind barbs (in knots) at the level of the injection on 22 July at hours (LT) (a) 08:00, (b) 10:00, (c) 12:00, (d) 14:00, (e) 16:00, and (f) 18:00.

diameter) is used. The size range of $0.039-10 \mu \mathrm{m}$ is typical of atmospheric aerosols (Seinfeld and Pandis, 2006). The relevant aerosol species here is sulfate $\left(\mathrm{SULF}=\mathrm{SO}_{4}^{2-}\right.$ $+\mathrm{HSO}_{4}^{-}$). The size bins are defined by their lower and upper dry particle diameter, so water uptake or loss does not transfer particles between bins (Zaveri et al., 2008). Only the Wexler et al. (1994) parameterization of $\mathrm{H}_{2} \mathrm{SO}_{4}-\mathrm{H}_{2} \mathrm{O}$ homogeneous nucleation is used in MOSAIC (Zaveri et al., 2008). Transfer of the mass between size bins and particle growth due to condensation and coagulation is computed using the two-moment approach described by Tzivion et al. (1989). The aerosol optical properties, such as extinction, single-scattering albedo, and the asymmetry factor for scattering, are calculated as a function of wavelength and threedimensional position. The refractive index, which is associ- ated for each chemical constituent of the aerosol, is calculated by volume averaging for each size bin, and Mie theory is used to estimate the extinction efficiency and the scattering efficiency. For efficient computation of the extinction and the scattering efficiencies, WRF-Chem uses a methodology described by Ghan et al. (2001). After the aerosol radiative properties are calculated they are used in the shortwave radiative transfer model. A Dudhia shortwave radiative scheme is applied in our study to calculate the downward solar radiation flux, taking into account the diurnal variation of the solar zenith angle (Dudhia, 1989).

For this study we use version 3.1.1 of WRF-Chem, using the two-way nest option to increase resolution in an inner domain. The coarse model domain is configured covering the western United States with a horizontal resolution of 
(a)

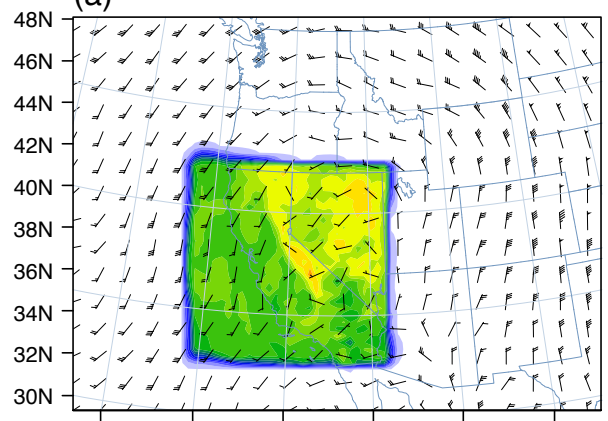

(c)

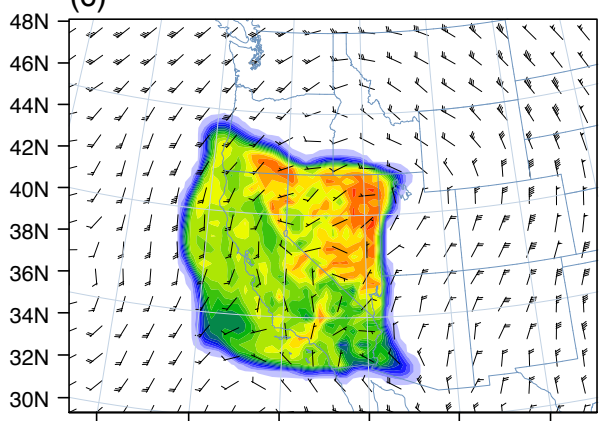

(e)

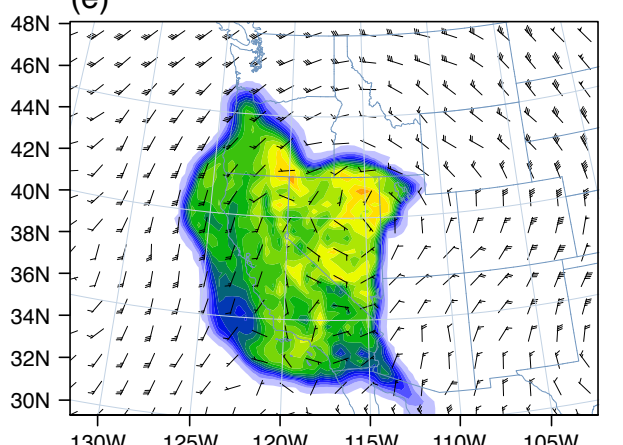

(b)

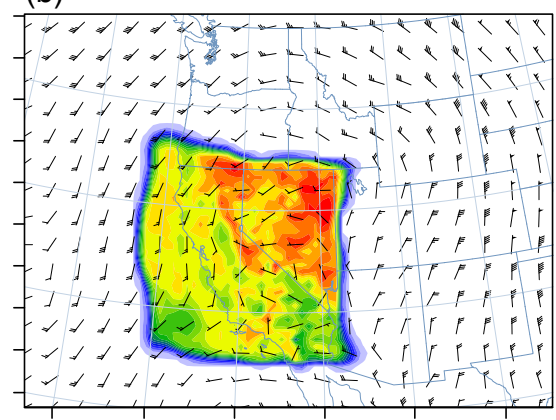

(d)

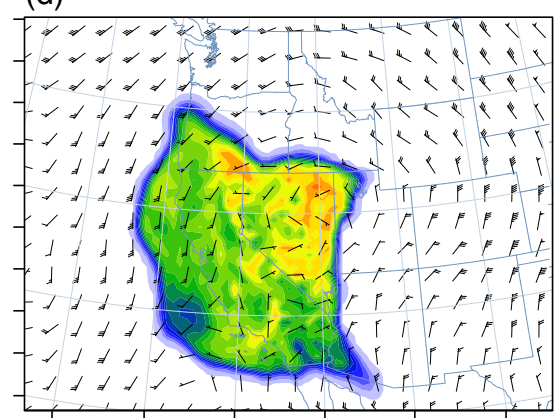

(f)

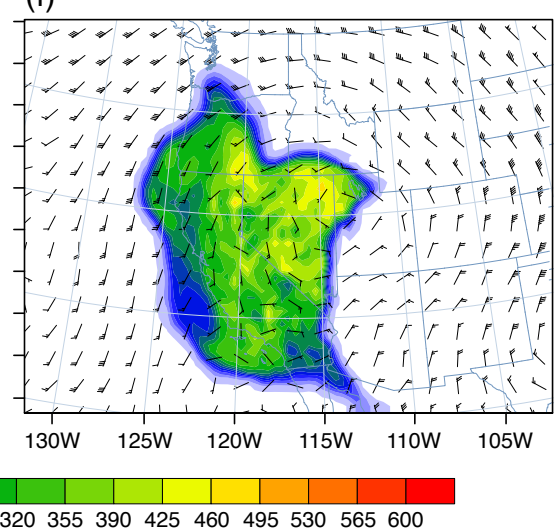

Fig. 4. Bin 2 sulfate aerosol mixing ratios ( $\mu \mathrm{g} \mathrm{kg}^{-1}$ of dry air) and wind barbs (in knots) at the level of the injection on $23 \mathrm{July}$ at hours (LT) (a) 08:00, (b) 10:00, (c) 12:00, (d) 14:00, (e) 16:00, and (f) 18:00.

$36 \mathrm{~km}$ and $80 \times 60$ grid points, and the fine domain of California and Nevada with a horizontal resolution of $12 \mathrm{~km}$ and $97 \times 97$ grid points. The fine domain corresponds to the area shown in Fig. 1. The vertical structure of the model is 28 grid points with the top of the model at $50 \mathrm{hPa}$. The initial and lateral boundary conditions for meteorological variables are obtained from the National Centers for Environmental Prediction Eta/North American Mesoscale model data set with $40 \mathrm{~km}$ spatial resolution at $3 \mathrm{hr}$ intervals (available from the Research Data Archive data set number ds609.2 maintained at the National Center for Atmospheric Research http://dss.ucar.edu). Sea surface temperatures are specified from the same data set. The WRF-Chem emissions for all anthropogenic chemical species are based on the EPA 2005 National Emissions Inventory (NEI 05). This setup follows the same model configuration as is validated by Chen et al. (2010) during a field campaign in May 2010 in California. A similar configuration of WRF over California is used in several studies and evaluated against observations for various events (Bao et al., 2008; Lu et al., 2012). Chapman et al. (2009) used WRF-Chem with the MOSAIC aerosol scheme to study the radiative impact of elevated point sources, which showed good agreement with observed data.

In the set of model experiments considered here, we directly inject sulfate aerosols at a single model level at $12.1 \mathrm{~km}$ (reasons for the choice of altitude are discussed below) over an idealized region which varies with the experiment. The sulfate aerosols are distributed into the four MOSAIC size bins following size distribution prescribed in the standard simulation (Fast et al., 2006; Zaveri et al., 2008). 
(a)

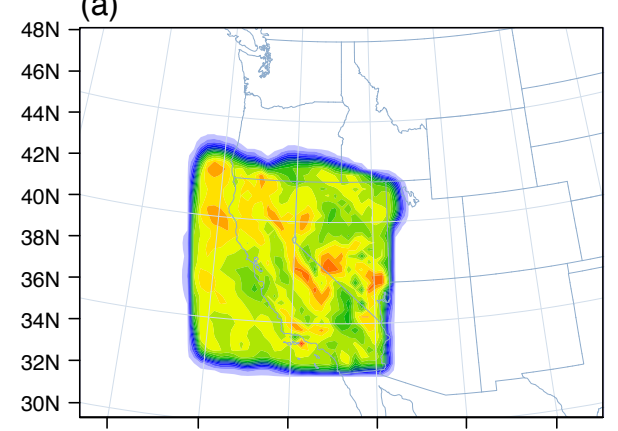

(c)

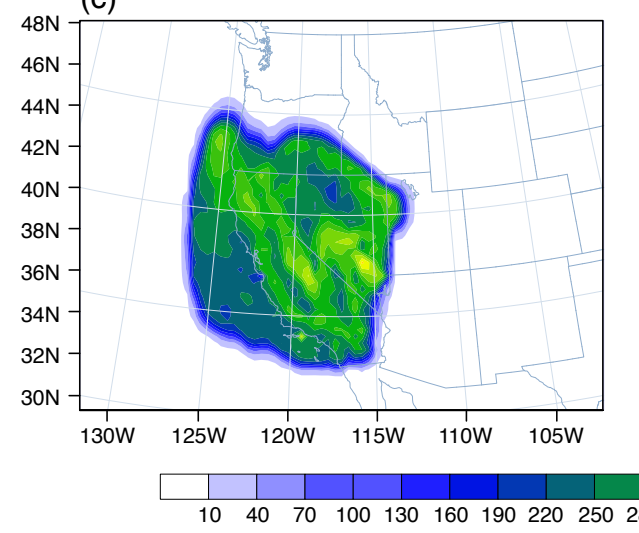

(b)

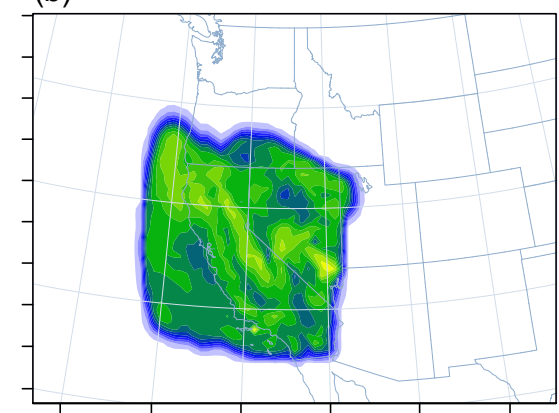

(d)

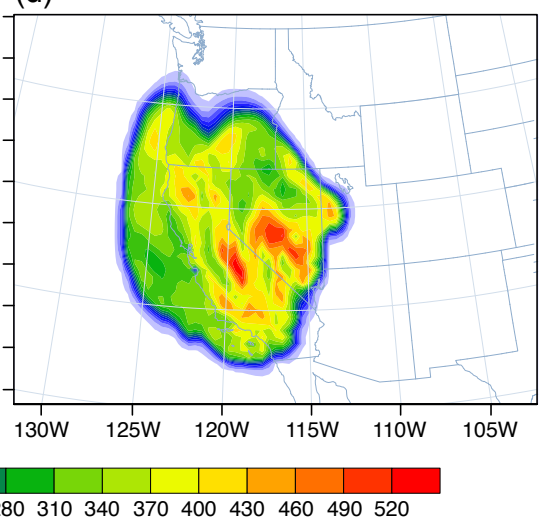

Fig. 5. Downward surface shortwave flux reductions $\left(\mathrm{Wm}^{-2}\right)$ between large-scale $30 \mu \mathrm{g} \mathrm{m}^{-2} \mathrm{~s}^{-1}$ experiment and the control on $22 \mathrm{July}$ at hours (LT) (a) 10:00, (b) 12:00, (c) 14:00, and (d) 16:00.

This choice of following exactly the setup used in regional air quality simulations with WRF-Chem is ad hoc, in the sense that geoengineering emissions might follow a different distribution. However, it makes this aspect of our setup a simple, widely used choice used in the air quality community. The choice of four size-bins follows the air quality simulation standard practice, a compromise between resolving explicitly the aerosol size distribution and computational considerations (Seinfeld and Pandis, 2006). The size distribution of the injected aerosols as used here (and by the regional air quality community) is representative of observed size distributions of ambient surface air aerosols. Note that we are not assuming that these particles are being formed from the gas phase (via chemical reactions and subsequently nucleation, condensation or coagulation) after injection of $\mathrm{SO}_{2}$ or $\mathrm{H}_{2} \mathrm{SO}_{4}$ as was done in previous efficacy studies (Heckendorn et al., 2009; Pierce et al., 2010; English et al., 2012). Rather we are injecting particles that have a size distribution typical of surface air. We return to the implications of this assumption at the appropriate point in the discussion. There is certainly room for further study considering optimal size distribution or methods of engineering particles in the regional context, but for initial consideration, this simple injection procedure making use of standard WRF-Chem assumptions appears to be a useful approach. In the discussion below we will summarize the sulfate aerosol emission rates for this stratospheric injection in mass units $\mu \mathrm{g} \mathrm{m}^{-2} \mathrm{~s}^{-1}$, noting that the associated number concentration distributions are computed according to the standard model treatment for surface sulfate aerosol emissions. The emissions are done on the $12 \mathrm{~km}$ fine grid over the specified subdomain in each experiment. The evolution of the bin distribution and aerosol growth will be discussed in Sect. 3.3.

We perform sets of experiments in which the rate of emission of sulfate aerosols per unit area and the size of the geographic area over which injection is assumed to occur are varied, respectively, as summarized in Table 1 . In each case the injection is done over an area of idealized spatial shape, and the sequence of experiments moves from what we term a large-scale injection region that covers all of California (plus some surrounding regions) to successively smaller scales. Injection areas roughly corresponding to the size of Southern California and the San Joaquin Valley are referred to as regional scale, while the smallest injection areas considered here, equivalent to $48 \mathrm{~km} \times 36 \mathrm{~km}$, correspond to roughly a metropolitan scale. One of the main effects to be illustrated in the sequence of smaller areas is the impact of advection effects and mixing effects from the edges of the injection region as a function of scale, while noting the total mass of injected aerosol required for each experiment. The evaluation over the large-scale area permits the impacts on surface temperature to be evaluated as a function of emission rate per 
(a)

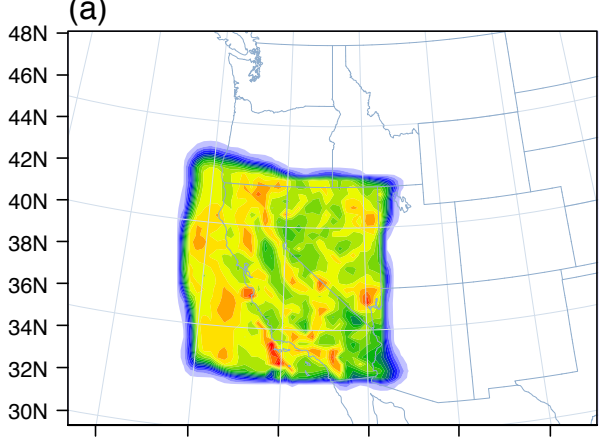

(c)

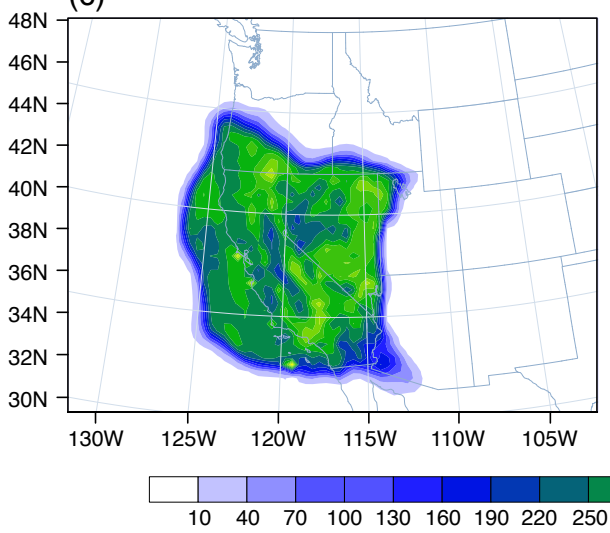

(b)

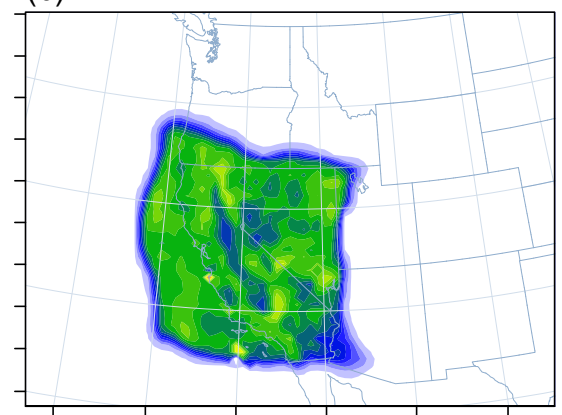

(d)

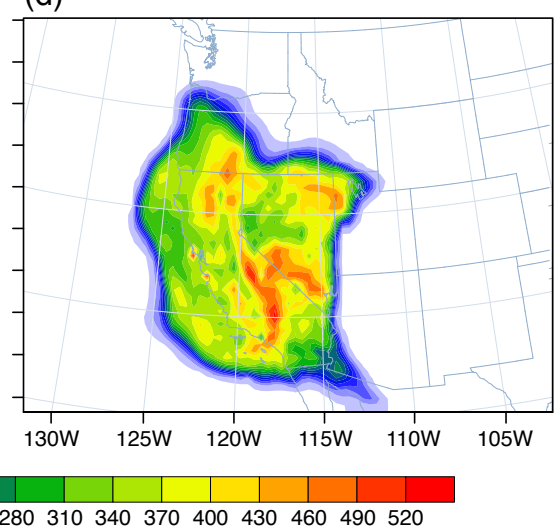

Fig. 6. Downward surface shortwave flux reductions $\left(\mathrm{Wm}^{-2}\right.$ ) between large-scale $30 \mu \mathrm{g} \mathrm{m}{ }^{-2} \mathrm{~s}^{-1}$ experiment and the control on 23 July at hours (LT) (a) 10:00, (b) 12:00, (c) 14:00, and (d) 16:00.

Table 1. Description of the experiments and their purposes as discussed in Sects. 3 and 4. Asterisk denotes the case used to illustrate spatial patterns in Figs. 3-8.

\begin{tabular}{|c|c|c|c|}
\hline Experiment name & $\begin{array}{l}\text { Emis. area } \\
{\left[\mathrm{km}^{2}\right]}\end{array}$ & $\begin{array}{l}\text { Emis. rate } \\
{\left[\mu \mathrm{g} \mathrm{m}^{-2} \mathrm{~s}^{-1}\right]}\end{array}$ & Purpose \\
\hline (1) Large-Scale & $1 \times 10^{6}$ & $6 ; 10 ; 20 ; 30 * ; 60$ & $\begin{array}{l}\text { Evaluate scaling of response } \\
\text { with emission rate over region. }\end{array}$ \\
\hline $\begin{array}{l}\text { (2) Large-Scale } \\
\text { illustration case* }\end{array}$ & $1 \times 10^{6}$ & 30 & $\begin{array}{l}\text { Evaluate local sensitivity over } \\
\text { region with approximately homoge- } \\
\text { neous cloud. }\end{array}$ \\
\hline $\begin{array}{l}\text { (3) Regional Scale } \\
\text { (SoCal; San } \\
\text { Joaquin Valley } \\
\text { cases) }\end{array}$ & $\begin{array}{l}69 \times 10^{3} \\
48 \times 10^{3}\end{array}$ & 30 & $\begin{array}{l}\text { Evaluate advection effects for } \\
\text { regional-scale injections. }\end{array}$ \\
\hline $\begin{array}{l}\text { Metropolitan or } \\
\text { targeted agricultural } \\
\text { scale }\end{array}$ & $\begin{array}{l}1.7 \times 10^{3} ; \\
1.7 \times 10^{3}\end{array}$ & 30 & $\begin{array}{l}\text { Evaluate advection effects } \\
\text { for smaller horizontal scale } \\
\text { injections. }\end{array}$ \\
\hline
\end{tabular}

unit area in a context where horizontal mixing edge effects are relatively small. It further permits local sensitivity of the surface response to a relatively homogeneous aerosol cloud to be seen.

The set of experiments varying sulfate aerosol emission rates over a range $\left(6,10,20,30\right.$, and $\left.60 \mu \mathrm{g} \mathrm{m}^{-2} \mathrm{~s}^{-1}\right)$ is performed using the large-scale injection area to evaluate the impact of the magnitude of the emission rate, as well as the local sensitivity within this region. Results at example grid points - one in the Los Angeles region $\left(34.05^{\circ} \mathrm{N}\right.$; $118.25^{\circ} \mathrm{W}$ ) and another in the Central Valley region (Fresno, $36.75^{\circ} \mathrm{N} ; 119.77^{\circ} \mathrm{W}$ ) - are seen as a function of the emission rate in Fig. 2. For the figures presented throughout, we have chosen the experiment with emissions rate of $30 \mu \mathrm{g} \mathrm{m}^{-2} \mathrm{~s}^{-1}$ as typifying the results (termed the large-scale illustration case in Table 1). Caveats on the response as a function of 
emission rate are discussed in Sect. 3.2, but this figure is useful for choosing a representative experiment with which to examine spatial and temporal evolution of the regional-scale impacts. Given the magnitude of the surface temperature response (around $6{ }^{\circ} \mathrm{C}$ at the time shown in Fig. 2), this case produces a signal strong enough to be well above the level of numerical noise in the simulated response, as well as to be relevant to real-world applications. Of course, the exact temperature reduction necessary to achieve a particular end, such as the avoidance of a certain number of deaths, or reduction of economic damage, would be context dependent and is beyond the scope of the estimates here. Similar spatial patterns to those presented below are found in all the large-scale experiments, with amplitude proportional to the emission rate. The amplitude of the injections will be discussed in more detail in Sect. 3.2. For the time of the aerosol injection, we have chosen a $2 \mathrm{hr}$ period in the morning, from 06:00 LT to 08:00 LT, so we can see the effect of the aerosols on the full diurnal cycle. The experiment is repeated independently on each of two days of the heat wave (22 and 23 July, 2006), as discussed in Sect. 3.3. Variations on the initial timing will be considered in Sect. 4 for smaller scale experiments, which are more sensitive to the period over which the cloud is advected.

\section{Large-scale idealized experiment}

\subsection{Advective effect}

Figures 3 and 4 show the spatial patterns of sulfate aerosol mixing ratio for a key size bin, bin 2 (chosen for its close relationship to shortwave impact in Fig. 2), evolving as a function of time on 22 and 23 July from emission in a simple square shape, for the large-scale injection experiment illustration case. Injection over such a large-scale region would likely be impractical for any real-world application but this experiment serves to illustrate regional differences in the temperature response under an area of relatively similar solar response. A first point from Fig. 3 is that advection does not rapidly carry the aerosol cloud outside of the domain, even for injections at $12.1 \mathrm{~km}$ altitude. Figure 3 also demonstrates the importance of vertical advection, not just horizontal, leading to the inhomogeneities in the concentrations inside of the injections square. Furthermore, the level of aerosol injection has been chosen according to meteorology, an example of a strategy that can be advantageous to the regional application for each particular heat wave event. We chose the level of $12.1 \mathrm{~km}$ as the level of aerosol injection, which has a relatively low wind speed, as estimated from the morning wind values over two important target regions - Los Angeles and the Central Valley. This helps reduce the rate at which the aerosol cloud is advected. This altitude is near the tropopause - considerably lower than would be typically chosen for a global geoengineering application - and so also serves to illustrate a trade-off between regional and large-scale considerations discussed in Sects. 3.3 and 6.

\subsection{Amplitude of the emissions}

Figure 2 shows each bin mixing ratio together with surface temperature and surface shortwave radiation reductions as a function of aerosol emissions for the two sample locations. Within the context of the emission assumptions outlined in Sect. 2, there is a highly linear relation between emissions, sulfate mixing ratios in bin $2(0.156-0.625 \mu \mathrm{m})$, and shortwave radiation differences for both regions, although the temperature response curve differs from one region to another. We underline again the caveats discussed in Sect. 2 regarding the linearity of the relationship between emission rates and the solar radiation reduction depending on the details of the emission strategy, microphysics, etc., as has been discussed for the global case (Robock, 2008; Heckendorn et al., 2009; Pierce et al., 2010; English et al., 2012). At high gas-phase emission rates, less than proportionate increases in, for instance, aerosol optical depth can occur (English et al., 2012). For the aerosol injection experiments here, the temperature response curve has a linear relation with bin 2 mixing ratios and shortwave differences in the Central Valley area, reaching a reduction of about $11^{\circ} \mathrm{C}$ in the case of a $60 \mu \mathrm{g} \mathrm{m}^{-2} \mathrm{~s}^{-1}$ aerosol injection. In the Los Angeles area, the temperature response increases in the case of an aerosol emission higher than $6 \mu \mathrm{g} \mathrm{m}^{-2} \mathrm{~s}^{-1}$ and achieves a maximum of $8^{\circ} \mathrm{C}$ in the case of the highest aerosol emission rate. Each of the bin mixing ratio curves behaves similarly in the two locations. The mixing ratio curve of bin $1(0.039-0.156 \mu \mathrm{m})$, which has the finest particles, increases and stabilizes after reaching $22 \mu \mathrm{g} \mathrm{kg}^{-1}$ of dry air at an aerosol emission of $6 \mu \mathrm{g} \mathrm{m}^{-2} \mathrm{~s}^{-1}$. The mixing ratio curve of bin $3(0.625-$ $2.5 \mu \mathrm{m}$ ) increases since the aerosol emission is higher than $6 \mu \mathrm{g} \mathrm{m}^{-2} \mathrm{~s}^{-1}$. The mixing ratio of bin $4(2.5-10.0 \mu \mathrm{m})$ is very low but shows a slight increase with aerosol emission increases. For the case of $30 \mu \mathrm{g} \mathrm{m}^{-2} \mathrm{~s}^{-1}$ aerosol emission, the shortwave reduction of about $200 \mathrm{Wm}^{-2}$ corresponds to approximately a $18 \%$ reduction in incoming surface shortwave relative to the control. Each of these estimates would have to be reviewed quantitatively using more refined emissions assumptions and microphysics were this regional application to be taken to the next stage of evaluation. For present purposes, Fig. 2 documents model behavior under the aerosol injection assumptions, and sets the stage for examining questions of the regional-scale response.

\subsection{Shortwave radiation and temperature for large-scale injection case}

Figures 5 and 6 show the downward surface shortwave response at times corresponding to Figs. 3 and 4, respectively. These are shown as reductions in the downward shortwave, i.e., as the control minus the experiment, to display positive 
(a)

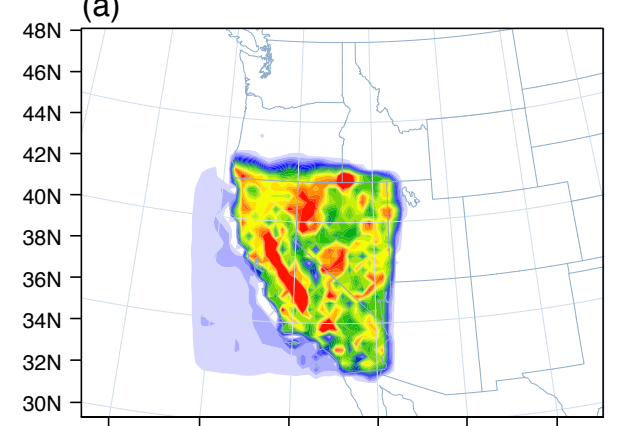

(c)

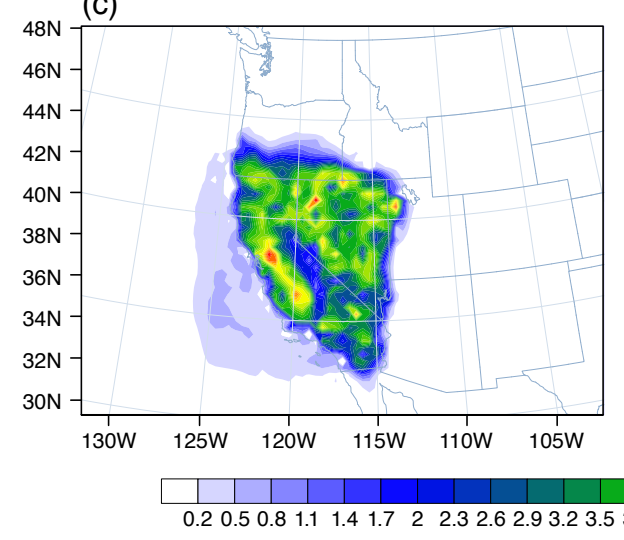

(b)

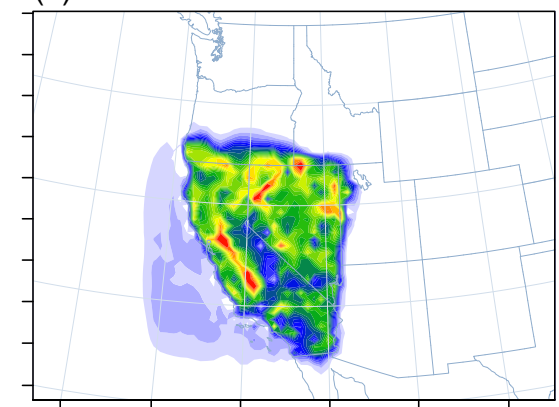

(d)

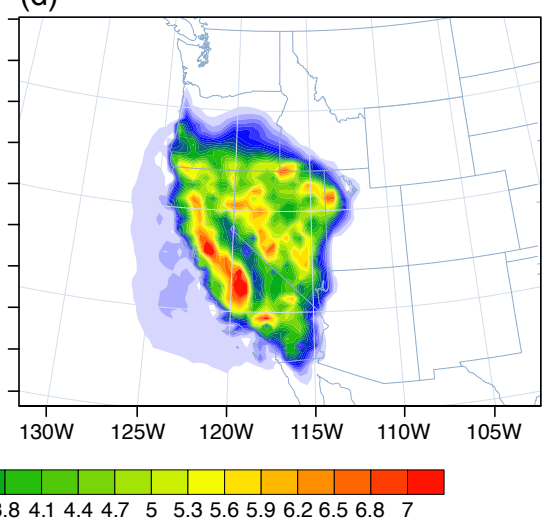

Fig. 7. Surface air temperature reductions $\left({ }^{\circ} \mathrm{C}\right.$ ) between large-scale $30 \mu \mathrm{g} \mathrm{m}^{-2} \mathrm{~s}^{-1}$ experiment and the control on 22 July at hours (LT) (a) 10:00, (b) 12:00, (c) 14:00, and (d) 16:00.

values. In the middle of the day, the overall size of the impact is a decrease of about $350 \mathrm{Wm}^{-2}$ (out of roughly $1100 \mathrm{Wm}^{-2}$ ). Aerosols were injected during morning hours, between 06:00 and 08:00 LT. The selection of time for inserting aerosols depends on them not being carried out of the target region too quickly. Inserting them in the early morning allows them more time to act before reaching the time of maximum temperature and aids examination of impact on the diurnal cycle.

The impact of these shortwave reductions by the aerosol cloud for surface air temperature may be seen in Figs. 7 and 8. For the chosen rate of emissions in this experiment, the impacts are substantial. Regional differences in the sensitivity of the response may be noted. One example is the greater Los Angeles region, which has less impact for a given level of sulfate aerosol concentrations than does the Central Valley. This appears to be consistent with the fact that the Los Angeles region tends to be strongly ventilated by wind flow from the ocean, while the Central Valley's maximum temperatures tend to be strongly affected by local balances involving radiative transfer and boundary layer turbulence.

Comparing the runs for 22 and 23 July indicates the modest effects of slightly different day to day flow patterns within the heat wave (23 July was slightly hotter than 22 July). The results of sulfate mixing ratio, downward shortwave flux re- ductions, and surface air temperature reductions are shown in Figs. 4, 6, and 8, respectively. The overall simulations for both days show a very similar pattern of surface shortwave and surface temperature reductions. The simulations of both days show significantly higher temperature reductions in the Central Valley, and the surface air temperature reductions in the middle of the day reach up to $7^{\circ} \mathrm{C}$ in that area. Thus to a first approximation, the shortwave and temperature reductions may be taken as typical of what would result for heat wave days with similar meteorology (within the bounds spanned by the two sample days here) in this region.

Turning to evolution of these effects over the day, Fig. 9 shows the sulfate aerosol mixing ratio of each size bin and aerosol number for each bin changing with time in the Los Angeles and the Central Valley areas. Rapid increase in the smallest-sized bin 1 is seen during the two hours of the injection, followed by an ongoing decrease after the end of injection in the second hour. The bin 2 mixing ratio increases for another two hours after the injection ends, associated with the conversion from bin 1 to 2 . Bins 3 and 4 increase slowly with time, tending to stabilize several hours after the injection.

The downward shortwave radiation and surface temperature time series, as well as the shortwave and temperature reductions (control-experiment) are shown in Fig. 10 for the Los Angeles and the Central Valley areas for both 22 and 

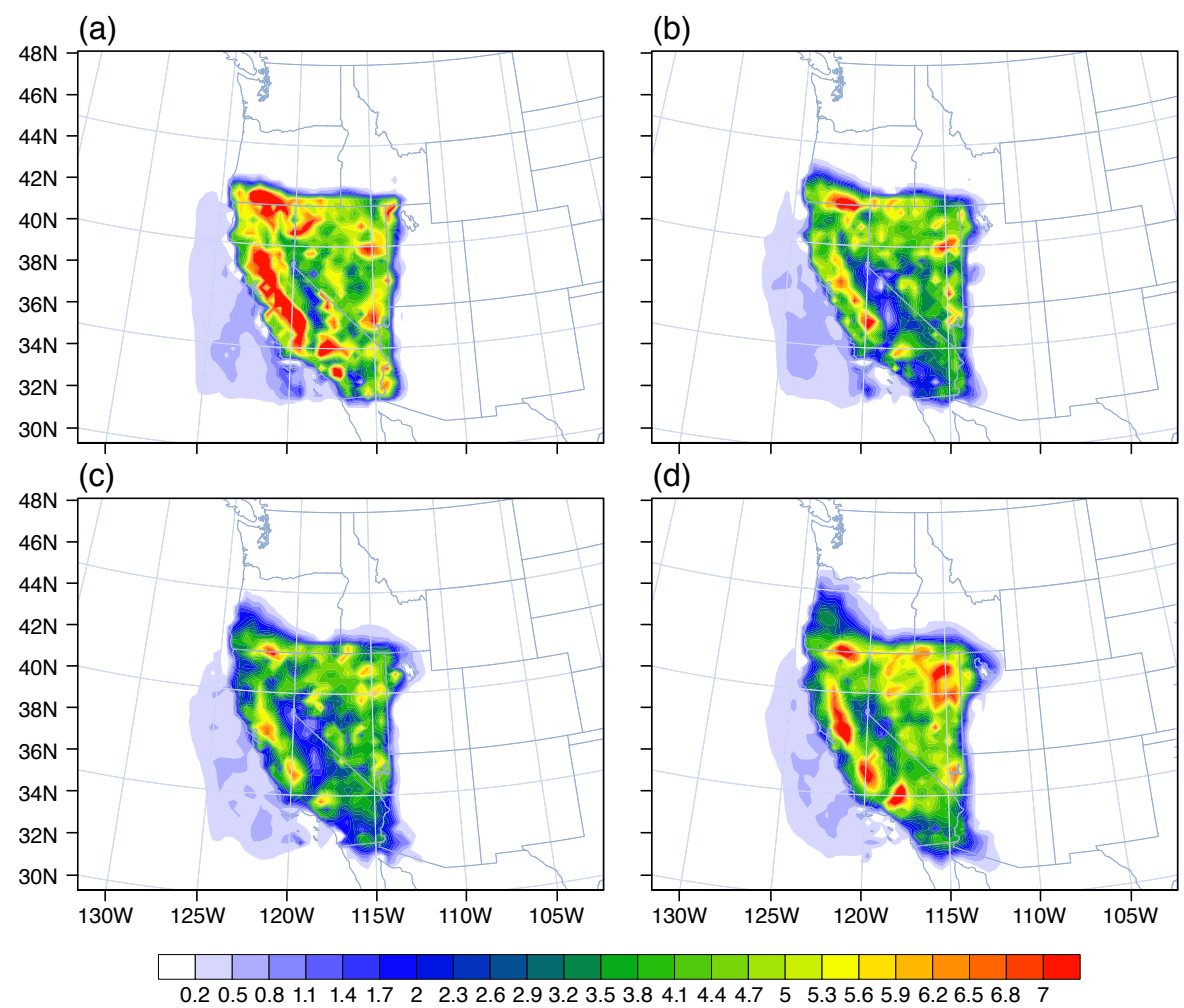

Fig. 8. Surface air temperature reductions $\left[{ }^{\circ} \mathrm{C}\right]$ between large-scale $30 \mu \mathrm{g} \mathrm{m}^{-2} \mathrm{~s}^{-1}$ experiment and the control on 23 July at hours (LT) (a) 10:00, (b) 12:00, (c) 14:00, and (d) 16:00.
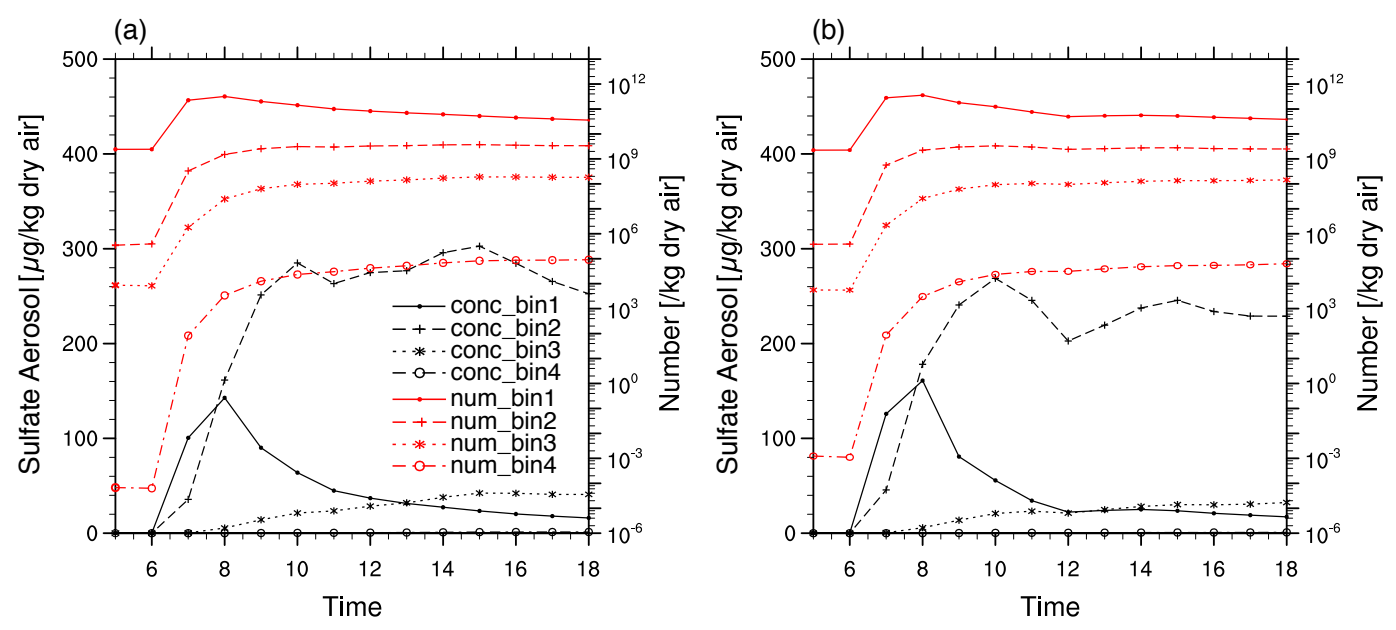

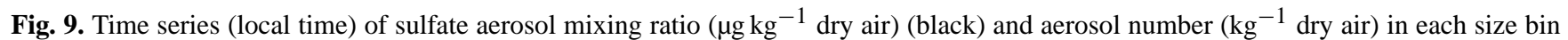
(red) at the level of the injection for 22 July for point locations (a) in Los Angeles and (b) in the Central Valley (Fresno). See Fig. 1 for point locations.

23 July. The pattern of shortwave reductions is similar for both days and for both areas. In each case, the shortwave reduction is slightly larger around 09:00 and 17:00 LT due to variation of total optical depth through the cloud with solar zenith angle. The temperature reduction differs from the Los Angeles to the Central Valley areas. The Central Val- ley surface temperature reduction has two clear peaks. One peak, about 16 to $17^{\circ} \mathrm{C}$, occurs in the morning at 09:00 LT, while the other peak, which reaches 19 to $21^{\circ} \mathrm{C}$, occurs in the evening at 18:00 LT. The Los Angeles temperature reduction has a peak of 7.5 to $9^{\circ} \mathrm{C}$ at 09:00 LT and another minor peak of about $5^{\circ} \mathrm{C}$ at 19:00 LT. In each case, the large peak in 
(a)

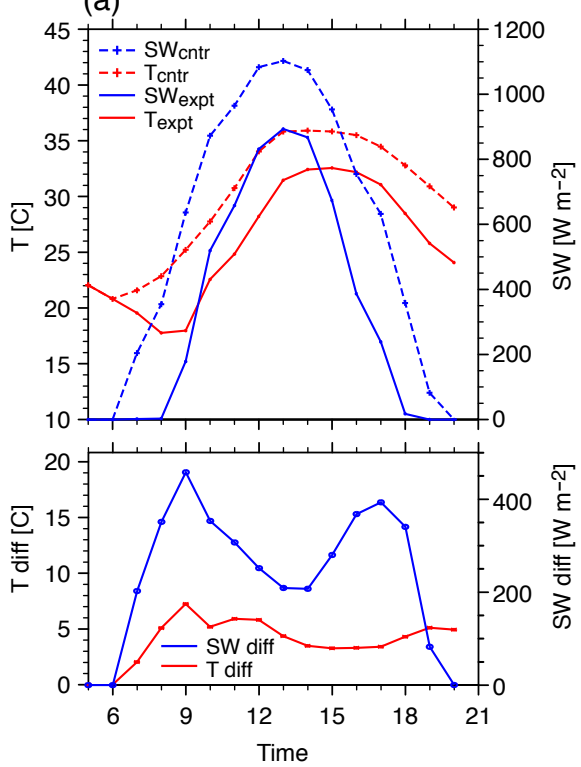

(c)

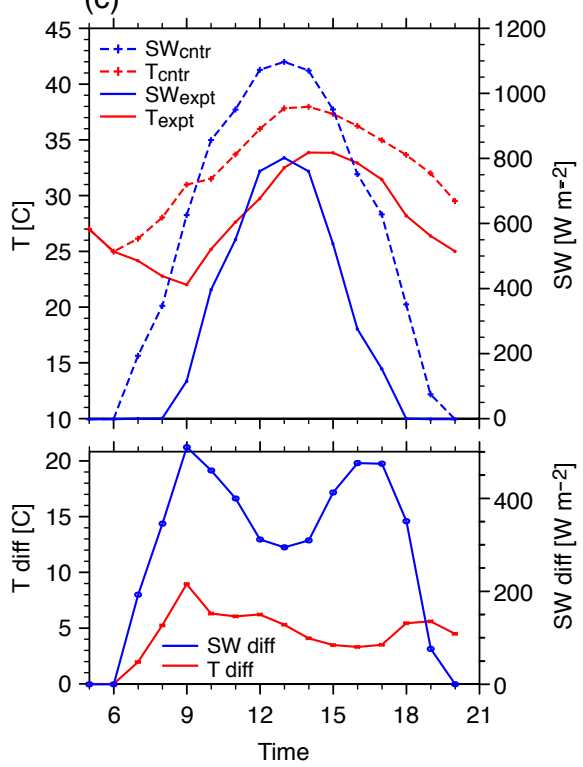

(b)

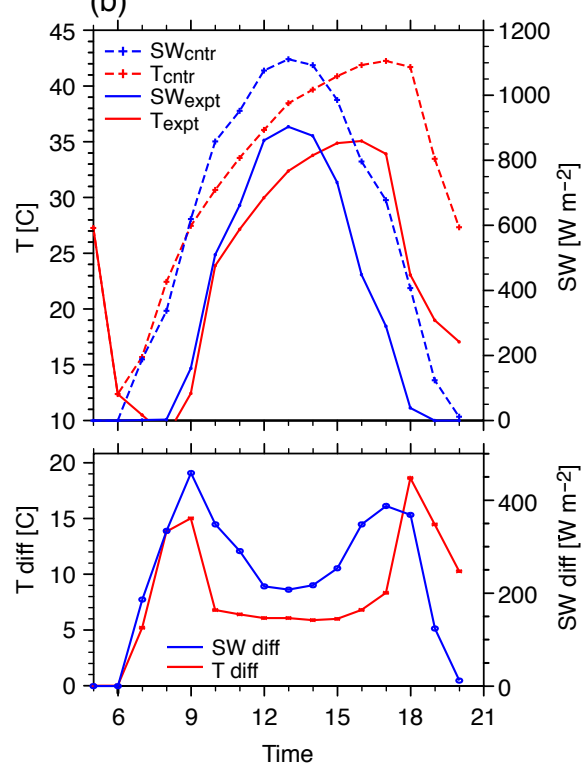

(d)

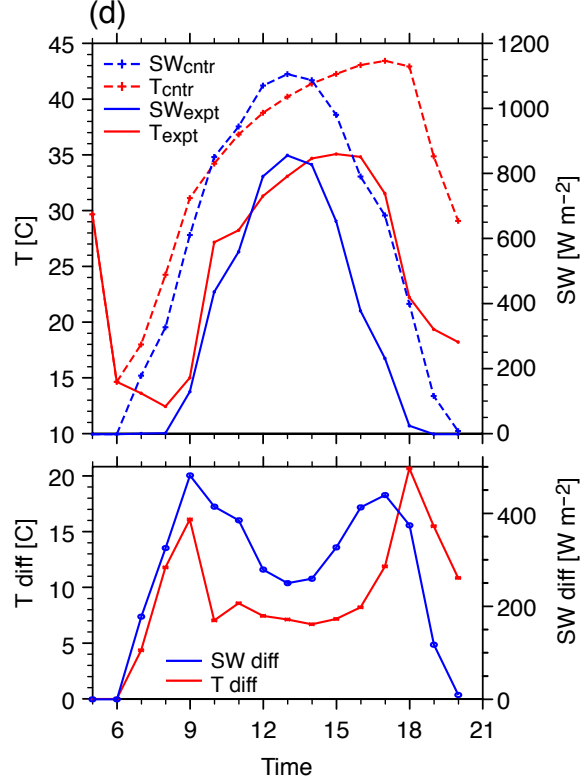

Fig. 10. Time series (local time) of surface air temperature $\left({ }^{\circ} \mathrm{C}\right)(\mathrm{red})$ and surface shortwave flux $\left(\mathrm{Wm}^{-2}\right)$ (blue); the upper panel shows the control run and experimental surface air temperature and surface shortwave radiation flux, and the lower panel shows the differences between the control run and the experimental surface air temperature and surface shortwave radiation flux for (a) Los Angeles, 22 July, (b) Central Valley (Fresno), 22 July, (c) Los Angeles, 23 July, and (d) Central Valley (Fresno), 23 July.

the reduction corresponds to the time of rapid increase or decrease of total temperature at the beginning or end of the day, effectively shortening the hot part of the day. In the Central Valley, the local meteorological balances in the control run yield the hottest part of the day in late afternoon, followed by a rapid drop in temperature, while in the experiment this is reduced by $7^{\circ} \mathrm{C}$, followed by an earlier drop in temperature. In Los Angeles, the lag of the hot part of the day, and the subsequent temperature drop, are each smaller, and the reduction of temperature more constant in the experiment.
The vertical profiles of the horizontal average of the sulfate aerosol mixing ratio, temperature, and wind speed are shown in Fig. 11 for the Los Angeles area (for a box from $33.6^{\circ} \mathrm{N}-$ $34.2^{\circ} \mathrm{N}, 118.6^{\circ} \mathrm{W}-120.2^{\circ} \mathrm{W}$ ) and in the Central Valley (for a box from $35.6^{\circ} \mathrm{N}-37.2^{\circ} \mathrm{N}, 118.6^{\circ} \mathrm{W}-120.2^{\circ} \mathrm{W}$ ). Box averages are used to ensure that the temperature and wind speed are representative. The wind speed shown is the mean of the wind speed over the box (not the speed of the mean wind) because this is a useful index of the strength of the advective effects seen in earlier figures. The bin 2 aerosol mixing 
ratio relative to the background is shown in Fig. 11a, where a spike may be seen at the injection level of $12 \mathrm{~km}$, which corresponds to $175 \mathrm{mb}$. This is shown at 18:00 LT to illustrate the results of vertical advection, diffusion and gravitational settling after 12 hours. The injection layer is a single model level (which is $30 \mathrm{mb}$ thick). Over this $12 \mathrm{hr}$ period, the vertical advection, diffusion, and gravitational settling have broadened the aerosol layer such that there are concentrations exceeding 1/1000th of the peak value through a layer approximately $150 \mathrm{mb}$ thick over Los Angeles and $240 \mathrm{mbar}$ over the Central Valley. At $380 \mathrm{mbar}$, the concentrations are close to the background, on the order of $10^{-2} \mu \mathrm{g} \mathrm{kg}^{-1}$. While no surface deposition occurs on the time scale of a day (for the conditions with no deep convection relevant here), the spreading in the vertical by the diffusive and advective effects is significant because, for the emission level used here, some of the aerosol clearly spreads into the upper troposphere. This can be important for downstream effects because of the possibility of wet deposition, as further discussed below.

The temperature is shown in Fig. 11b at 14:00 LT, when there is the strongest midday warming. There is essentially no effect at the level of injection because the aerosol is not absorbing significantly, but the surface effects extend through a lower-tropospheric layer. There is substantial near-surface warming extending through roughly the boundary layer; a much smaller warming continues in the lower free troposphere. A very slight cooling in the lower mid-troposphere is noted in the Central Valley, but the temperature perturbation is negligible above the mid-troposphere.

The vertical profile of the wind speed is shown in Fig. 11c. The control and experiment profiles are displayed for the wind speed averaged over the Los Angeles box and the central Valley box. Modest differences (less than $1 \mathrm{~m} \mathrm{~s}^{-1}$ ) in wind speed may be noted in the lower troposphere, associated with lower-tropospheric warming, but above the midtroposphere, the wind speed change is negligible in the experiment relative to the control. A point potentially significant for applications may also be noted from this figure. There is a minimum of wind speed occurring at approximately 175 mbar, and the level of injection has been chosen to correspond to this minimum speed. This choice has been made to illustrate some differences in factors that would be advantageous from the point of view of the regional application but not for larger-scale considerations. The level of the wind speed minimum is the same earlier in the day (and would be reasonably forecast) and so would naturally be chosen by decision makers conducting such an experiment to minimize advection effects. However, this choice would likely not be well suited for contributions to a global geoengineering stratospheric aerosol loading nor to minimize downstream effects because, as shown in Fig. 11a, aerosol concentrations spread fairly quickly into the upper troposphere, where wet deposition might occur downstream in a longer time frame.

\section{Smaller scale injection regions}

The large-scale idealized experiment serves to highlight regional differences in sensitivity and to provide a sense of the magnitude of temperature response for a given level of aerosol loading. However, these involve very large masses of injected aerosol (see Table 1) and are thus less likely to be under consideration for any practical implementation than would smaller areas. We thus consider examples that move towards more localized injection regions. For efficiency of presentation, we show two injection regions in a single experiment (the main effects are sufficiently local that they would be similar if separate experiments were carried out for each). For the regional-scale experiments, we specify one injection region over the area of Southern California and another one over the southern part of San Joaquin Valley, which is part of the Central Valley. The initial area coverage of the two regional-scale injection regions is $69 \times 10^{3} \mathrm{~km}^{2}$ and $48 \times 10^{3} \mathrm{~km}^{2}$ respectively. The smaller is roughly $1 / 22$ the size of the large-scale experiment injection area (the two together total about $1 / 9$ of the large-scale experiment). These still involve large amounts of aerosol as discussed below, but serve to illustrate the challenges that would arise at a regional scale. In particular, advective effects will become increasingly important to take into account with respect to specific target regions.

Here the examples provide shading to the following: (i) a region extending from the greater Los Angeles metropolitan area down to San Diego and a large region to the east, and (ii) a region surrounding Fresno in the Central Valley and extending down to San Bernardino. It would be possible to tailor such regions more specifically to populated or agricultural areas, or to undertake continuous injections upstream of the region. The latter would have the trade-off of more precise spatial location versus reduction of concentration if a given total amount of injection is spread over a longer time interval. For simplicity, the example here is done with two hours of injections in the morning, as in the large-scale experiment, with the injection location and areal extent being estimated such that the cloud covers much of the target region for most of the day, even taking into account the advective movement. We use simple rectangular injection regions so that it is easy to visualize the impact of advection, but of course this would be optimized in any practical application using weather forecasts for wind fields. The estimates here use $12 \mathrm{hr}$ back trajectories from the Hybrid Single-Particle Lagrangian Integrated Trajectory (HYSPLIT) model (Draxler and Rolph, 2012).

Figures 12 and 13 show the surface shortwave and surface air temperature reductions relative to the control resulting from these injection patterns. At 10:00 LT, which is four hours after the injection begins, the cloud still resembles a slightly shifted and stretched version of the rectangular initial region. At 16:00 LT, the area of the aerosol cloud has altered substantially, but in a manner that is largely predictable 
(a)

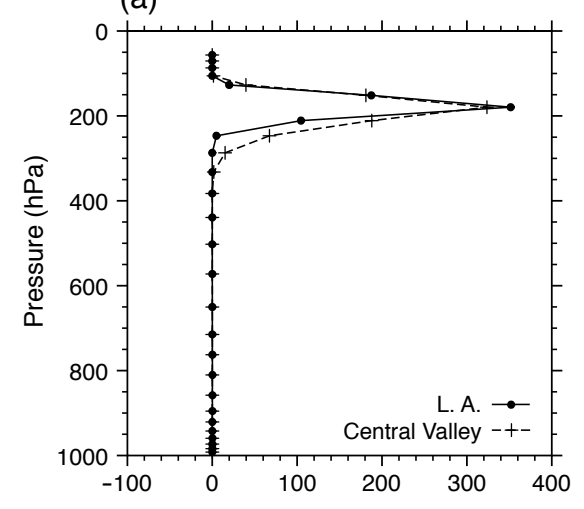

Bin 2 Sulfate aerosol Exp-Ctrl $\left(\mu \mathrm{g} \mathrm{Kg}^{-1}\right.$ dry air $)$ (b)

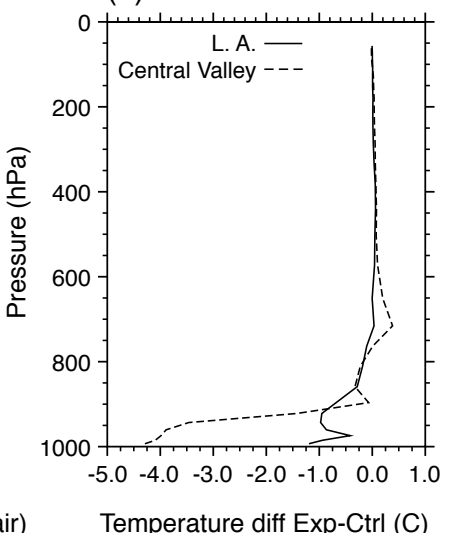

(c)

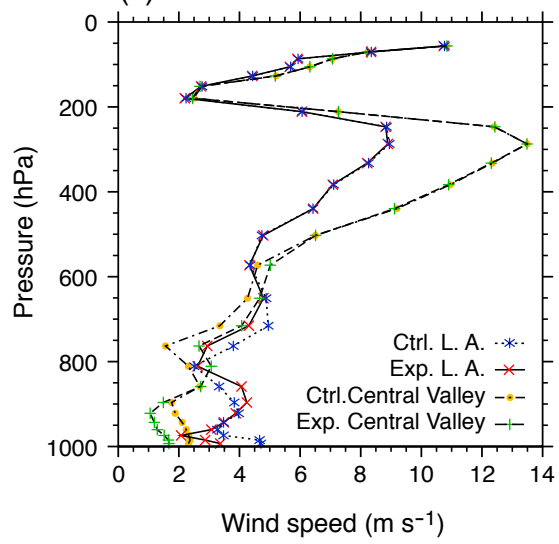

Fig. 11. Vertical profiles on 22 July in the Los Angeles area and in the Central Valley (see text for respective horizontal averaging areas) of (a) the sulfate aerosol mixing ratio difference (experiment minus control) $\left(\mu \mathrm{g} \mathrm{kg}{ }^{-1}\right.$ dry air) at 18:00 LT, (b) temperature difference $\left({ }^{\circ} \mathrm{C}\right)$ at 14:00 LT, and (c) wind speed $\left(\mathrm{m} \mathrm{s}^{-1}\right)$ at 14:00 LT.

(a)

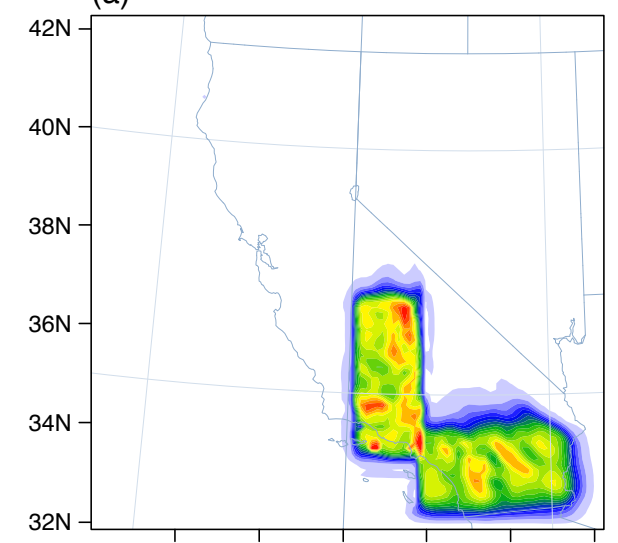

(c)

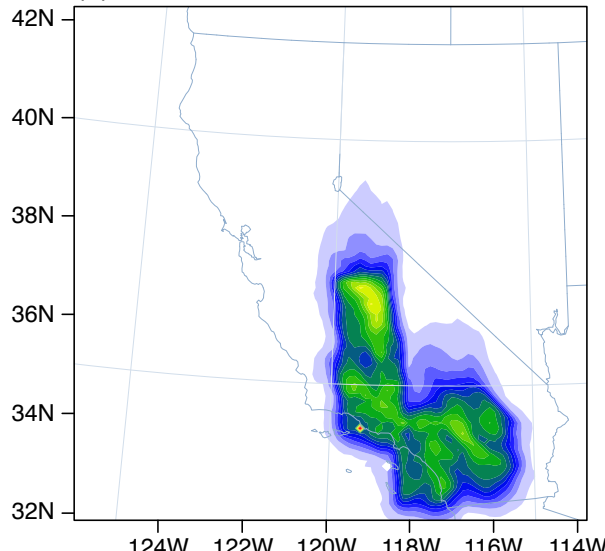

124W 122W 120W 118W 116W 114W (b)

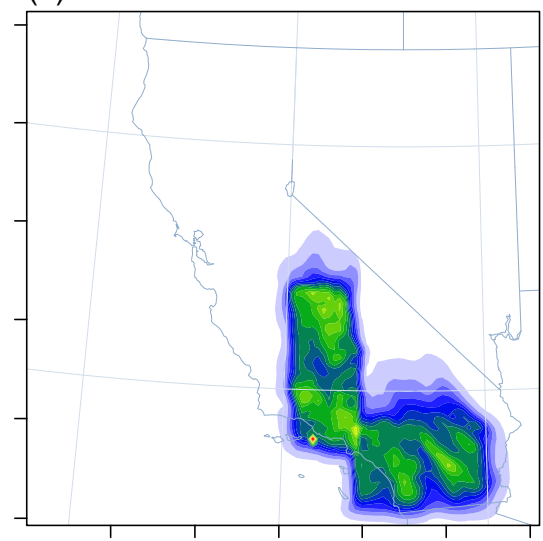

(d)

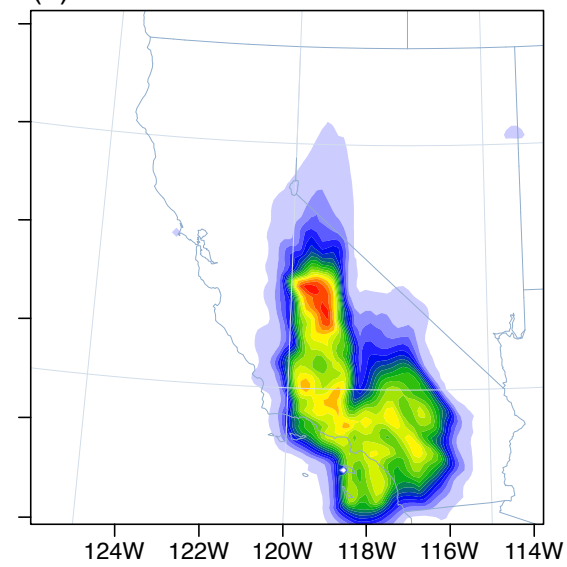

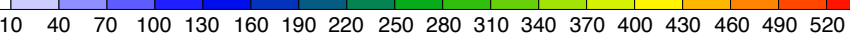

Fig. 12. Downward surface shortwave flux reductions $\left(\mathrm{Wm}^{-2}\right.$ ) on 22 July at hours (LT) (a) 10:00, (b) 12:00, (c) 14:00, and (d) 16:00 for the smaller-scale injection experiments. 
(a)

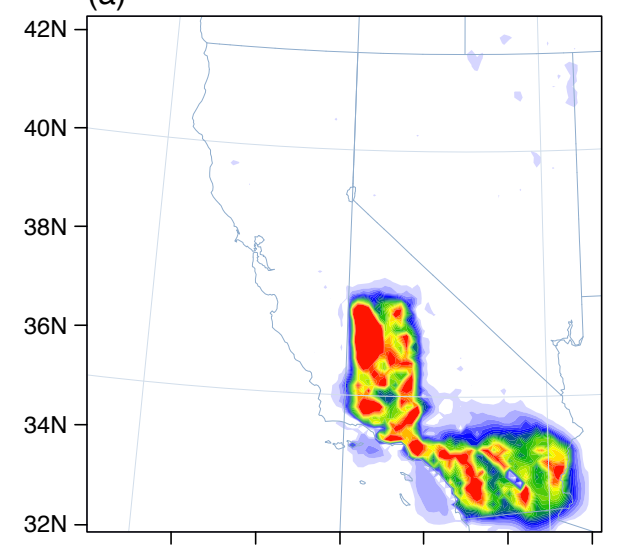

(c)

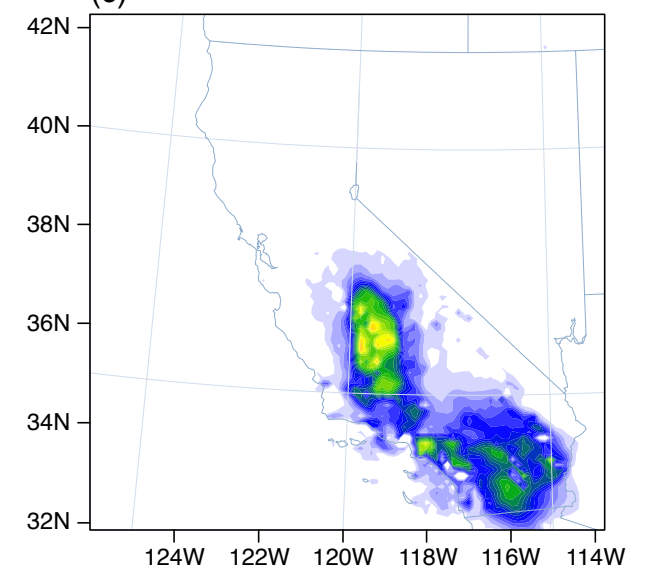

(b)

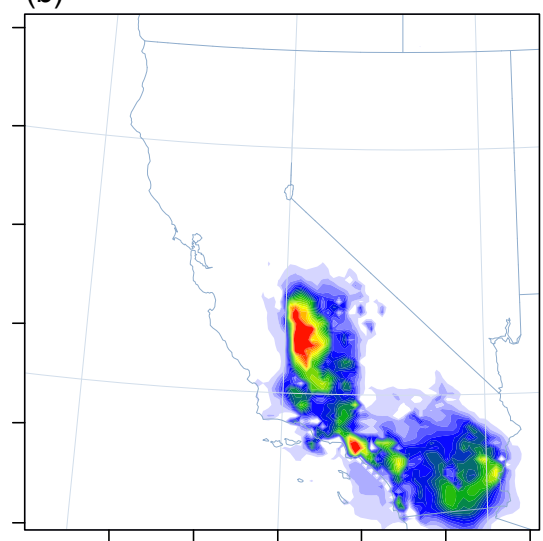

(d)

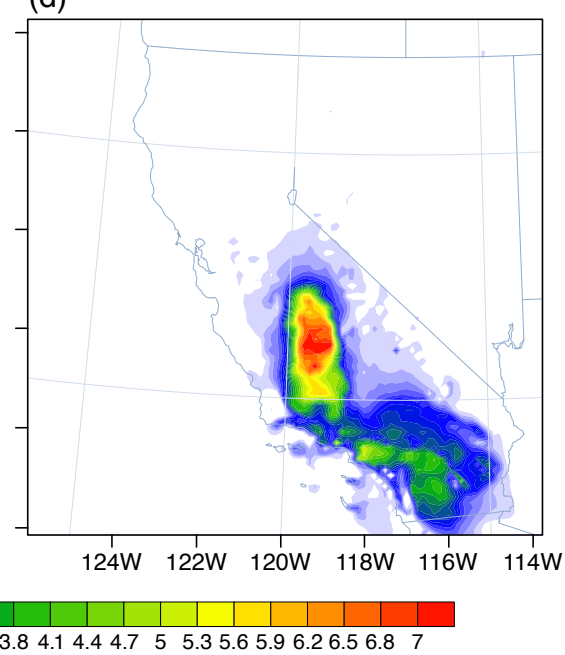

Fig. 13. Surface air temperature reductions $\left({ }^{\circ} \mathrm{C}\right)$ on 22 July at hours (LT) (a) 10:00, (b) 12:00, (c)14:00, and (d) 16:00 for the smaller-scale injection experiments.

from the flow field. In this test, we chose an initial injection region such that the cloud would not drift over the ocean within $12 \mathrm{~h}$, although some part of the cloud covers unpopulated areas over the desert. From the evolution of the shortwave pattern in Fig. 12, one can infer that coverage for an area comparable to Los Angeles could plausibly be achieved with overall injections one quarter to one tenth the size, although this would require careful consideration of the flow pattern.

The amplitude of the shortwave difference and surface air temperature reductions within each region are very similar to those in the large-scale area test shown in Figs. 5 and 7, but the values of shortwave and surface air temperature are slightly smaller due to the mixing of clean air from outside the cloud.

Smaller metropolitan and targeted agricultural injection areas both of $1.7 \times 10^{3} \mathrm{~km}^{2}$ are chosen to illustrate the impacts of advection and mixing as one moves further down in horizontal scale. One area covers Los Angeles metropolitan area and another one covers agricultural area over Fresno.
Because the aerosol cloud travels further relative to its horizontal dimension, we also illustrate the impact of injection time chosen later in the day, which reduces the prediction problem of the path the cloud will travel toward a desired target region. Injection here is done from 11:00-13:00 LT. Figure 14 shows the surface air temperature and surface shortwave flux reductions at 14:00 LT and 16:00 LT relative to the control. Surface air temperature and surface shortwave flux reductions tend to be smaller than the response in comparable areas in the experiments with larger injection areas shown in (c) and (d) of Figs. 5, 7, 12, and 13. At this scale, the edge effects associated with horizontal mixing of clear air into the cloud from the sides are becoming sufficiently important that even the response under the center of the cloud is not reaching the full response that would occur for larger area coverage.

There are thus trade-offs between advection and mixing having relatively stronger effects at smaller scales and the total amount of aerosol required at the larger scale. With this in mind, the total mass of aerosol injected provides some 

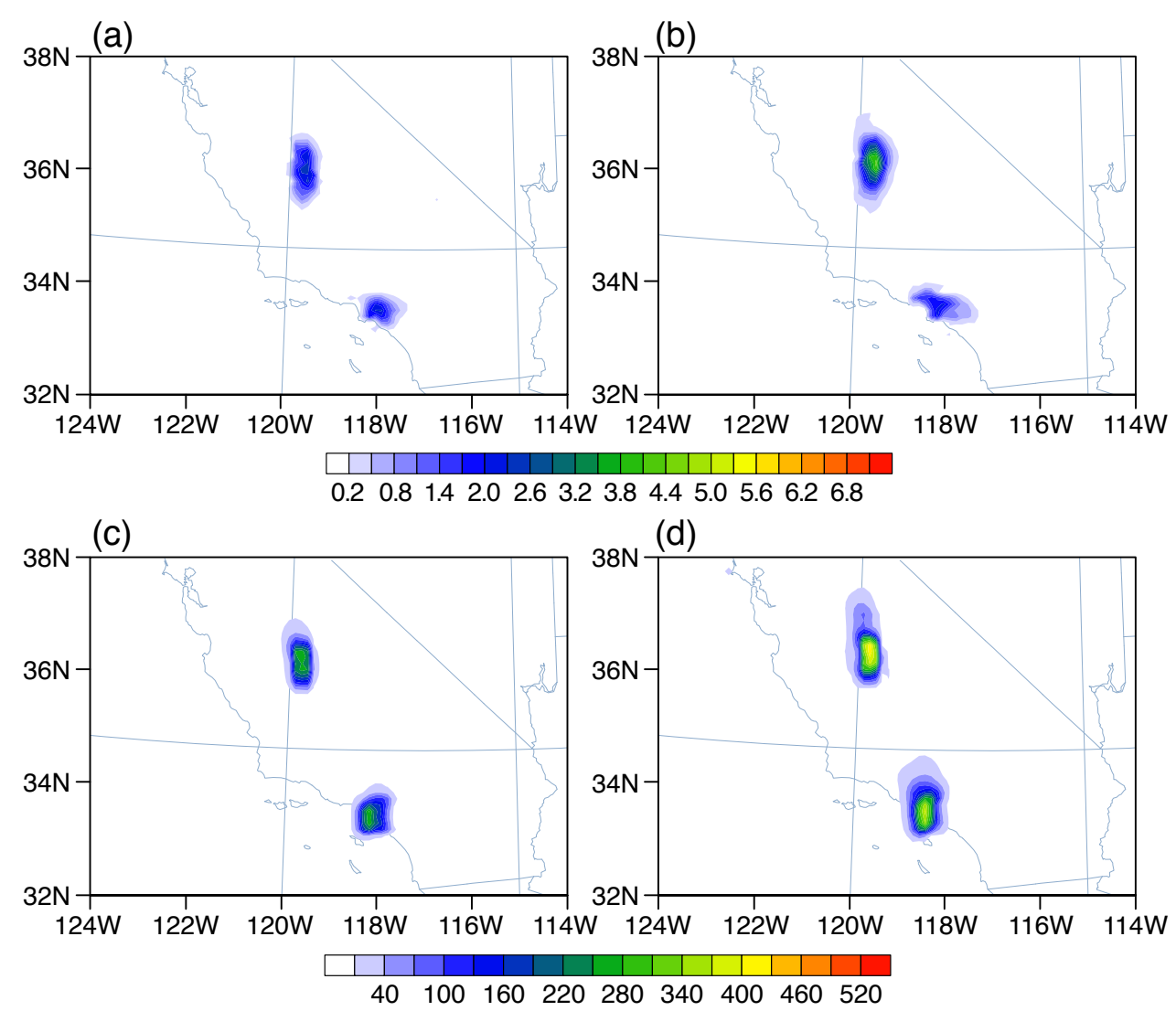

Fig. 14. (a) Surface air temperature reductions $\left[{ }^{\circ} \mathrm{C}\right]$ for the metropolitan-size injection experiments on $22 \mathrm{July}$ at 14:00 LT; (b) as in (a) but at 16:00 LT; (c) downward surface shortwave flux reductions $\left(\mathrm{Wm}^{-2}\right)$ on 22 July at 14:00 LT; and (d) as in (c) but for 16:00 LT.

perspective on the magnitude of the endeavor that would be implied by the different horizontal scales. The injection area that covers large parts of Southern California corresponds to approximately $15 \mathrm{Gg}$ of sulfate aerosols integrated over the region and over the $2 \mathrm{hr}$ injections interval for a given day. Compared to the $10 \mathrm{Tg} \mathrm{S}$ annual injection under recent consideration for global geoengineering applications (Pierce et al., 2010; English et al., 2012), this is a small fraction: roughly $1 / 2000$ th the size in terms of sulfur equivalent, using $1 \mathrm{TgS} \sim 3 \mathrm{Tg}$ aerosol particles. However, to provide a rough visualization of the mass of sulfate aerosols involved, this corresponds to a payload of about $120 \mathrm{C}-5 \mathrm{~s}$ (the largest US cargo jet, assuming $0.122 \mathrm{Gg}$ payload per plane) - i.e., a very substantial mass. The Los Angeles metropolitan injection area roughly corresponds to $0.36 \mathrm{Gg}$ of sulfate aerosol emitted over the $2 \mathrm{hr}$ interval, i.e., to approximately the payload of $3 \mathrm{C}-5 \mathrm{~s}$ (roughly $10^{-5}$ of the sulfur equivalent of the global case). It must be underlined that this amount is for just one day, for one heat wave, and for the one specific region.

\section{Testing via shortwave measurements}

In considering how one might test the effectiveness of such aerosol injections in a real-world experiment, the natural variability of temperature and the fact there is no control experiment must be taken into account. There would otherwise be no way of telling what temperature would have occurred in the absence of the aerosol release (Robock et al., 2010). However, downward shortwave reductions, such as those shown in Figs. 5 and 12 and the corresponding upward reflected solar at the top of the atmosphere, could be directly measured. The aerosol cloud spatial pattern is initially highly identifiable and can be tracked through time. This process would be made easier in this application because heat waves tend to occur at times with small cloud cover. In conjunction with other measurements, the shortwave reduction could be attributed to the injections with fairly high accuracy, and this can be used as the leading benchmark of the impact. To translate this to surface temperature reductions, one would then use data sets from comparable meteorological situations but with and without natural cloud cover to estimate the surface temperature reduction per decrease in surface shortwave flux. 


\section{Discussion and conclusions}

This study critically examines the potential for an aerosolinjection geoengineering strategy to be applied at a regional scale to reduce the impacts of a heat wave. If global-scale geoengineering proposals begin to move toward practical testing, there may be increasing motivation to consider regional applications, and so it is worth assessing in advance the size of the emission required to have a regional impact, and the associated implications and concerns. The sensitivity of surface temperature and the advection effects at the altitude of injection will both depend on the meteorology of the particular heat wave. Thus, a specific example is examined for the conditions of an observed heat wave with a regionalscale model to provide a sense of how substantial these effects will be.

The results indicate that a sufficiently large emission of sulfate aerosols can indeed have a substantial impact on surface air temperature, although the temperature response varies among areas. For instance, temperature response in the Central Valley is larger than that in the Los Angeles area. This is partially attributable to the topographical locations of the Central Valley and Los Angeles, as well as Los Angeles' close proximity to the Pacific Ocean, and was reproducible on both days of the 2006 heat wave. The temperature response during the hottest part of the day is a key factor in reducing heat wave impacts, and is roughly $7{ }^{\circ} \mathrm{C}$ in the Central Valley for the case of an emission of $30 \mu \mathrm{g} \mathrm{m}^{-2} \mathrm{~s}^{-1}$. The temperature reduction has a strong diurnal cycle, and is actually larger during the morning and late afternoon hours, due to the optical depth dependence on solar zenith angle. This has the effect of shortening the hot part of the day.

The temperature reduction scales monotonically with the magnitude of the aerosol injection, so the latter could be reduced to meet temperature targets. The flow field at the height of injection is a significant factor in the evolution of the aerosol cloud. Thus, the choice of the injection amplitude and height level would depend on the meteorology at the time of the heat wave. These appear to be within the realm that could be addressed by forecasting the flow, provided the injections would be carried out over regions at least as large as a greater metropolitan area. The choice of the height of the injection based on flow field characteristics would yield a trade-off between choices that would be better from the point of view of the regional application, and those that might be preferable from a larger-scale point of view. The case presented here uses a choice that might typify that of a decision maker choosing the injection height based solely on local considerations of minimal flow for a specific city at a time just before the start of the injections. The height used for illustration in this case is near the tropopause, at $12 \mathrm{~km}$ where the winds were relatively weak over Los Angeles and the Central Valley for this case. This is at lower altitude than would be optimal from the perspective of (i) global dispersion of the aerosol in the stratosphere, where it could contribute to reflecting solar radiation and reducing temperature at a global scale, and (ii) of minimizing aerosol load in the troposphere, where it would carry the risk of wet deposition in states downstream (Kravitz et al., 2009). This serves to illustrate that if such an approach were to be considered for actual application, there would need to be requirements established that those responsible for local injection decisions consider the downstream effects. It remains possible that some solution such as photophoretic levitation of engineered nanoparticles (Keith, 2010) could be devised to address some of these issues, but in the absence of such a development, these potential side effects would remain a concern. The case study here is over California, which has a history of attention to environmental protection, and thus might be expected to require careful oversight of such an activity if it should move towards application. However, it is worth raising the concern that a regional application might be undertaken in some other location with less consideration for potential side effects downstream.

For the injection area covering most of Southern California considered in Sect. 4, the sulfur equivalent of the aerosol injections on a given day is roughly 2000 times smaller than the $10 \mathrm{Tg}$ annual injection of sulfur being considered for global applications. One way of viewing these results would be that they indicate that sufficient shortwave can be reflected by an aerosol cloud to affect temperature on a regional scale if one is willing to inject sufficient aerosol and to develop means to do so - subject to further evaluation and much analysis of safety considerations. However, even for smaller areas, this would represent a very substantial amount of aerosol to be lofted. Furthermore, this would have to be done repeatedly at each heat wave and for each region. If, for instance, one were in a situation of seriously considering steps toward global geoengineering, the regional application might arise either as a means of testing the global application, or of timing the injection to produce additional regional benefit in terms of temperature reduction during heat waves. Indeed, further numerical study of the implications of the regional application may well be necessary because of the possibility that a regional government could undertake it unilaterally. Nonetheless, the initial estimates provided here of the amount of aerosol required, combined with concerns already raised in the literature, suggest that regional planners might be well advised to consider other strategies involving regional adaptation of infrastructure to protect against heat wave impacts.

This is reinforced by the fact that, in addition to potential negative downstream impacts such as on precipitation, or ozone layer depletion (e.g., Kravitz et al., 2009; Robock, 2008), the regional application has an additional, very substantial potential downside. To protect a populated region from the effects of the heat wave using such a method, the injections would have to be conducted over or just upstream from the populated area. Although local deposition is negligible over the time scale of the numerical experiments 
examined here, the proximity to population necessarily raises the attendant concern for possible local negative effects or the public perception of these effects. Considerations for the local safety of the emission process would be much greater than those potentially arising from injections over a remote, unpopulated region, as could be done for global geoengineering applications.

Thus, while a regional-scale application may have sufficient motivation to make it worth further assessment in model simulations, the considerations noted here are consistent with recommendations from assessment of global-scale applications (Robock et al., 2008; Heckendorn et al., 2009; English et al., 2012) that the downsides of geoengineering with sulfate aerosols suggest that they should not be counted on as a good alternative to mitigation via reduction of fossilfuel emissions.

\section{Supplementary material related to this article is available online at: http://www.atmos-chem-phys.net/13/ 6373/2013/acp-13-6373-2013-supplement..pdf.}

\begin{abstract}
Acknowledgements. This study was supported in part by National Science Foundation grant AGS-1102838. We acknowledge WRF-Chem developers for the public domain WRF-Chem code, S. Peckham for assistance with WRF-Chem code modification, and the NOAA Air Resources Laboratory (ARL) for the provision of the HYSPLIT transport and dispersion model used in this publication. We thank J. E. Meyerson for graphical assistance, and A. Robock, D. Keith, S. Paulson, J. Stutz, and others for discussion, and acknowledge comments by two anonymous reviewers.
\end{abstract}

Edited by: T. Butler

\section{References}

Bao, J. W., Michelson, S. A., Persson, P. O. G., Djalalova, I. V., and Wilczak, J. M.: Observed and WRF-simulated low-level winds in a high-Ozone episode during the Central California ozone study, J. Appl. Meteorol. Clim., 47, 2372-2394, 2008.

Barnard, J. C., Fast, J. D., Paredes-Miranda, G., Arnott, W. P., and Laskin, A.: Technical Note: Evaluation of the WRF-Chem "Aerosol Chemical to Aerosol Optical Properties" Module using data from the MILAGRO campaign, Atmos. Chem. Phys., 10, 7325-7340, doi:10.5194/acp-10-7325-2010, 2010.

Brovkin, V., Petoukhov, V., Claussen, M., Bauer, E., Archer, D., and Jaeger, C.: Geoengineering climate by stratospheric sulfur injections: Earth system vulnerability to technological failure, Clim. Change, 92, 243-259, 2009.

Budyko, M. I.: Climate and Life, Academic Press, New York, USA, 508 pp., 1974.

Chan, A. K., Hyde, R. A., Myhrvold, N. P., Tegreene, C. T., and Wood, L. L.: High Altitude atmospheric injection system and method, US Patent Application Publication: US 2010/0071771, Publication Date: March 25, 2010.

Chapman, E. G., Gustafson Jr., W. I., Easter, R. C., Barnard, J. C., Ghan, S. J., Pekour, M. S., and Fast, J. D.: Coupling aerosolcloud-radiative processes in the WRF-Chem model: Investigating the radiative impact of elevated point sources, Atmos. Chem. Phys., 9, 945-964, doi:10.5194/acp-9-945-2009, 2009.

Chen, D., Li, Q., Stutz, J., Pikelnaya, O., Tsai, J. Y., Haman, C. L., Lefer, B. L., Flynn, J. H., Roberts, J. M., de Gouw, J. A., Holloway, J. S., Veres, P. R., Gilman, J. B., and Kuster W. C.: Evaluation of WRF/Chem simulations of meteorology, $\mathrm{O}_{3}$ and $\mathrm{NO}_{\mathrm{y}}$ in the Los Angeles Basin during CalNex 2010, American Geophysical Union Fall Meeting, San Francisco, California, USA, 13-17 December 2010, A21C-0121, 2010.

Chen, F. and Dudhia, J.: Coupling an advanced land-surface (hydrology model with the Penn State (NCAR MM5 modeling system. Part I: Model description and implementation, Mon. Weather Rev., 129, 569-585, 2001.

Crutzen, P. J.: Albedo enhancement by stratospheric sulfur injections: A contribution to resolve a policy dilemma?, Clim. Change, 77, 211-220, 2006.

Draxler, R. R. and Rolph, G. D.: HYSPLIT (HYbrid Single-Particle Lagrangian Integrated Trajectory) Model access via NOAA ARL READY Website (http://ready.arl.noaa.gov/HYSPLIT.php, last access: 2 March 2012), NOAA Air Resources Laboratory, Silver Spring, MD, 2012.

Dudhia, J.: Numerical study of convection observed during the winter monsoon experiment using a mesoscale two-dimensional model, J. Atmos. Sci., 46, 3077-3107, 1989.

English, J. M., Toon, O. B., and Mills, M. J.: Microphysical simulations of sulfur burdens from stratospheric sulfur geoengineering, Atmos. Chem. Phys., 12, 4775-4793, doi:10.5194/acpd-122517-2012, 2012.

Fast, J. D., Gustafson Jr., W. I., Easter, R. C., Zaveri, R. A., Barnard, J. C., Chapman, E. G., Grell, G. A., and Peckham, S. E.: Evolution of ozone, particulates, and aerosol direct radiative forcing in the vicinity of Houston using a fully coupled meteorology-chemistry-aerosol model, J. Geophys. Res., 111, D21305, doi:10.1029/2005JD006721, 2006.

Gershunov, A., Cayan, D. R., and Iacobellis, S. F.: The great 2006 heat wave over California and Nevada: Signal of an increasing trend, J. Climate, 22, 6181-6203, 2005.

Ghan, S., Laulainen, N., Easter, R., Wagener, R., Nemesure, S., Chapman, Y., Zhang, E., and Leung, R.: Evaluation of aerosol direct radiative forcing in MIRAGE, J. Geophys. Res., 106, 52955316, 2001.

Grell, G. A. and Devenyi, D.: A generalized approach to parameterizing convection combining ensemble and data assimilation techniques, Geophys. Res. Lett., 29, 1693, doi:10.1029/2002GL015311, 2002.

Grell, G. A., Peckham, S. E., Schmitz, R., McKeen, S. A., Frost, G., Skamarock, W. C., and Eder, B.: Fully coupled "online" chemistry within the WRF model, Atmos. Environ., 37, 6957-6975, 2009.

Grell, G. A.: Coupled weather chemistry modeling, in: Large-Scale Disasters: Prediction, Control, Mitigation, edited by: M. Gad-elHak, Cambridge University Press, 302-317, 2008.

Grell, G. A., Fast, J. D., Gustafson, Jr., W. I., Peckham, S. E., McKeen, S. A., Salzmann, M., and Freitas, S.: On-line chemistry 
within WRF: description and evaluation of a State-of-the-Art multiscale air quality and weather prediction model, in: Integrated systems of meso-meteorological and chemical transport models, edited by: Baklanov, A., Mahura, A., and Sokhi, R., Springer, Heidelberg, Germany, 41-54, 2011.

Heckendorn, P., Weisenstein, D., Fueglistaler, S., Luo, B. P., Rozanov, E., Schraner, M., Thomason, L. W., and Peter, T.: The impact of geoengineering aerosols on stratospheric temperature and ozone, Environ. Res. Lett., 4, 045108, doi:10.1088/17489326/4/4/045108, 2009.

Hong, S.-Y., Dudhia, J., and Chen, S.-H.: A revised approach to ice microphysical processes for the bulk parameterization of clouds and precipitation, Mon. Weather Rev., 132, 103-120, 2004.

Jones, A., Haywood, J., Boucher, O., Kravitz, B., and Robock, A.: Geoengineering by stratospheric $\mathrm{SO}_{2}$ injection: results from the Met Office HadGEM2 climate model and comparison with the Goddard Institute for Space Studies ModelE, Atmos. Chem. Phys., 10, 5999-6006, doi:10.5194/acp-10-5999-2010, 2010.

Intergovernmental Panel on Climate Change: Contribution of Working Group I to the Fourth Assessment Report of the Intergovernmental Panel on Climate Change, Climate Change 2007: The Physical Science Basis, Solomon, S., Qin, D., Manning, M., Chen, Z., Marquis, M., Averyt, K. B., Tignor, M., and Miller, H. L., Cambridge University Press, Cambridge, UK, 2007.

Keith, D. W.: Geoengineering the Climate: History and Prospect, Annu. Rev. Energ. Env., 25, 245-284, 2000.

Keith, D. W.: Photophoretic levitation of engineered aerosols for geoengineering, P. Natl. Acad. Sci., 107, 16428-16431, 2010.

Klemp, J. B., Skamarock, W. C., and Dudhia, J.: Conservative splitexplicit time integration methods for the compressible nonhydrostatic equations, Mon. Weather Rev., 135, 2897-2913, 2007.

Kravitz, B., Robock, A., Oman, L., Stenchikov, G., and Marquardt, A.B.: Sulfuric acid deposition from stratospheric geoengineering with sulfate aerosols, J. Geophys. Res., 114, D14109, doi:10.1029/2009JD011918, 2009.

Kravitz, B., Robock, A., Boucher, O., Schmidt, H., Taylor, K. E., Stenchikov, G., and Schulz, M.: The Geoengineering Model Intercomparison Project (GeoMIP), Atmos. Sci. Lett., 12, 162167, 2011.

Lu, W., Zhong, S., Charney, J. J., Bian, X., and Liu, S.: WRF simulation over complex terrain during a southern California wildfire event, J. Geophys. Res., 117, D05125, doi:10.1029/2011JD017004, 2012.

Matthews, H. D. and Caldeira, K.: Transient climate-carbon simulations of planetary geoengineering, P. Natl. Acad. Sci. USA, 104, 9949-9954, 2007.

Mesinger, F., Dimego, G., Kalnay, E., Mitchell, K., Shafran, P. C., Ebisuzaki, W., Jovi, D., Woollen, J., Rogers, E., Berbery, E. H., Ek, M. B., Fan, Y., Grumbine, R., Higgins, W., Li, H., Lin, Y., Manikin, G., Parrish, D., and Shi, W. : North American Regional Reanalysis, B. Am. Meteorol. Soc., 87, 343-360, doi:10.1175/BAMS-87-3-343, 2006.

Niemeier, U., Schmidt, H., and Timmreck, C.: The dependency of geoengineered sulfate aerosol on the emission strategy, Atmos. Sci. Lett., 12, 189-194, 2011.

Ostro, B. D., Roth, L. A., Green, R. S., and Basu, R.: Estimating the mortality effect of the July 2006 California heat wave, Environ. Res., 109, 614-619, 2009.
Pierce, J. R., Weisenstein, D. K., Heckendorn, P., Peter, T., and Keith, D. W.: Efficient formation of stratospheric aerosol for climate engineering by emission of condensible vapor from aircraft, Geophys. Res. Lett., 37, L18805, doi:10.1029/2010GL043975, 2010.

Rasch, P. J., Crutzen, P. J., and Coleman, D. B.: Exploring the geoengineering of climate using stratospheric sulfate aerosols: The role of particle size, Geophys. Res. Lett., 35, L02809, doi:10.1029/2007GL032179, 2008.

Rasch, P. J., Tilmes, S., Turco, R. P., Robock, A., Oman, L., Chen, C., Stenchikov, G. L., and Garcia, R. R.: An overview of geoengineering of climate using stratospheric sulphate aerosols, Philos. T. Roy. Soc. A, 366, 4007-4037, 2008.

Ricke, K. L., Rowlands, D., Ingram, W. J., Keith, D. W., and Morgan, M. G.: Effectiveness of stratospheric solar radiation management as a function of climate sensitivity, Nat. Clim. Change, 2, 92-96, 2011.

Robock, A.: Volcanic eruptions and climate, Rev. Geophys., 38, 191-219, 2000.

Robock, A.: The climatic aftermath, Science, 295, 1242-1244, 2002.

Robock, A.: 20 reasons why geoengineering may be a bad idea, B. Am. Meteorol. Soc., 64, 14-18, 2008.

Robock, A., Oman, L., and Stenchikov, G. L.: Regional climate responses to geoengineering with tropical and Arctic $\mathrm{SO}_{2}$ injections, J. Geophys. Res., 113, D16101, doi:10.1029/2008JD010050, 2008.

Robock, A., Marquardt, A., Kravitz, B., and Stenchikov, G.: Benefits, risks, and costs of stratospheric geoengineering, Geophys. Res. Lett., 36, L19703, doi:10.1029/2009GL039209, 2009.

Robock, A., Bunzl, M., Kravitz, B., and Stenchikov, G. L.: A Test for geoengineering?, Science, 327, 530-531, 2010.

Seinfeld, J. H. and Pandis, S.N.: Atmospheric Chemistry and Physics: From Air Pollution to Climate Change, 2 Edn., WileyInterscience, 2006.

Soden, B. J., Wetherald, R. T., Stenchikov, G. L., and Robock, A.: Global Cooling After the Eruption of Mount Pinatubo: A Test of Climate Feedback by Water Vapor, Science, 296, 727-730, 2002.

Tilmes, S., Muller, R., and Salawitch, R.: The sensitivity of polar ozone depletion to proposed geoengineering schemes, Science, 320, 1201-1204, 2008.

Trenberth, K. E., and Dai, A.: Effects of Mount Pinatubo volcanic eruption on the hydrological cycle as an ana$\log$ of geoengineering, Geophys. Res. Lett., 34, L15702, doi:10.1029/2007GL030524, 2007.

Tzivion, S., Feingold, G., and Levin, Z.: The evolution of raindrop spectra. Part II: collisional collection/breakup and evaporation in a rainshaft, J. Atmos. Sci., 46, 3312-3327, 1989.

Volodin, E. M., Kostrykin, S. V., and Ryaboshapko, A. G.: Climate response to aerosol injection at different stratospheric locations, Atmos. Sci. Lett., 12, 381-385, 2011.

Wexler, A. S., Lurmann, F. W., and Seinfeld, J. H.: Modelling urban and regional aerosols. Part I: Model development, Atmos. Environ., 28, 531-546, 1994.

Wigley, T. M. L.: A Combined mitigation/geoengineering approach to climate stabilization, Science, 314, 452-454, 2006.

Zaveri, R. A., Easter, R. C., Fast, J. D., and Peters, L. K.: Model for Simulating Aerosol Interactions and Chemistry (MOSAIC), J. Geophys. Res., 113, D13204, doi:10.1029/2007JD008782, 2008. 